\title{
Psychological and Demographic Predictors of Plastic Bag Consumption in Transaction Data
}

\author{
Rosa Lavelle-Hill \\ The Alan Turing Institute, UK \\ rlavelle-hill@turing.ac.uk \\ James Goulding \\ N/LAB, Nottingham University Business School, UK \\ james.goulding@nottingham.ac.uk \\ Gavin Smith \\ N/LAB, Nottingham University Business School, UK \\ David Clarke \\ School of Psychology, University of Nottingham, UK \\ Pete Bibby \\ School of Psychology, University of Nottingham, UK
}




\begin{abstract}
Despite the success of plastic bag charges in the UK, there are still around a billion single-use plastic bags bought each year in England alone, and the government have made plans to increase the levy from 5 to 10 pence. Previous research has identified motivations for bringing personal bags to a supermarket, but little is known about the individuals who are continuing to frequently purchase single-use plastic bags after the levy. In this study, over a million loyalty card transaction records from a high-street health and beauty retailer were harnessed to study 12,968 individuals' bag buying behaviour (analysed using descriptive statistics). Statistical regional differences in plastic bag buying throughout the UK occurred. From the transaction data 2,326 frequent single-use plastic bag buyers were identified and matched randomly to infrequent buyers, creating a balanced sub-sample which was used for predictive modelling $(N=4,652)$. For each individual in the modelling sample, their transaction data was matched to questionnaire responses measuring demographics, shopping motivations, and individual differences. Using this data, an exploratory machine learning approach was utilised to investigate the demographic and psychological predictors of frequent plastic bag consumption. It was found that frequent bag buyers spent more money in store, were younger, more likely to be male, less frugal, open to new experiences, and more displeased with their appearance (compared with infrequent bag buyers). Interestingly, environmental concerns did not predict plastic bag consumption, highlighting the disconnect between predicting pro-environmental attitudes and real world environmental behaviour.
\end{abstract}




\section{Psychological and Demographic Predictors of Plastic Bag Consumption in Transaction Data}

\section{Introduction}

\section{Plastic Bag Charges}

In 2014, 7.6 billion plastic bags were used by customers of English supermarkets (GOV, 2015; WRAP, 2015). That is on average 140 bags per person (GOV, 2015), and equates to approximately 61,000 tonnes of plastic (Smithers, 2016). Plastic bags are typically made from non-biodegradable high density polyethylene (HDPE), a material sourced from fossil fuels (Edwards \& Fry, 2011). As well as the energy and oil used to create them, most bags are not recycled (Monaghan, 2018) and negatively impact the environment when littered or inadequately disposed of (Jambeck et al., 2015). Plastic bags contribute to the 12.7 million tonnes of plastic that end up in our seas each year (Jambeck et al., 2015), polluting the waters and harming marine wildlife (Jambeck et al., 2015). Many national and local governments have introduced policies to try to reduce the number of bags used (Clapp \& Swanston, 2009), these include bans (e.g. in Kenya (NEMA, 2018)), and mandatory charges (e.g. in Ireland in 2002 (Anastasio and Nix, 2016)). In October 2015, England followed Scotland, Wales, and Northern Ireland in introducing a mandatory 5 pence charge for single use plastic bags, in an attempt to reduce the number of single-use plastic being consumed.

In England, the 5 pence charge has been successful in reducing the number of bags used by shoppers (DEFRA, 2018b) mirroring findings from other countries (Australia, 2015; Block, 2013; Haoran, 2010; Poortinga, Whitmarsh, \& Suffolk, 2013; Scottish Government, 2015; Welsh Government, 2016). England's six-month review post-levy showed that the number of single-use plastic bags had dropped by more than $85 \%$ to around 500 million in six months (DEFRA, 2018b). People's attitudes towards the levy had also changed (Poortinga, Sautkina, Thomas, \& Wolstenholme, 2016; Thomas, Sautkina, Poortinga, Wolstenholme, \& Whitmarsh, 2019). A longitudinal survey found that six months after the levy, there was increased support for the charges, and 
improved awareness of the environmental impact of household plastic waste (Poortinga et al., 2016; Thomas et al., 2019). When the surveyed respondents reduced their plastic bag consumption, it was reported to be for both financial and environmental reasons (Jakovcevic et al., 2014; Poortinga et al., 2016). Despite the reduction in plastic bag consumption, a supermarket observational study showed that there were no changes in the number of customers bringing personal bags, such as rucksacks, to the supermarket. The use of 'bags for life', however, did double after the levy - suggesting shoppers were replacing single-use bags with bags for life (Poortinga et al., 2016).

Studying real world environmental behaviour unobtrusively, whilst retaining detailed information about the individual, is a difficult task. Diary interview studies have teased out people's motivations and attitudes for buying plastic bags (Poortinga et al., 2016), but when using smaller samples it is harder to attest generalisability to the findings. Questionnaire and longitudinal surveys have reached a wider participant pool (He, 2010; Poortinga et al., 2016; Sharp, Høj, \& Wheeler, 2010), but self-reported behaviour measures can be affected by social desirability bias (Van de Mortel et al., 2008) or miss-remembering (Jakovcevic et al., 2014). Kormos and Gifford (2014), in a meta-analysis, found that $79 \%$ of the variance in the association between self-reported pro-environmental behaviour and objective pro-environmental behaviour remained unexplained. In other words, self-reported environmental behaviour does not strongly predict objective measures of environmental behaviour. This is especially troubling when interventions and campaigns are being devised on the results of studies using self-reported measures of behaviour. Therefore, if actual behaviour can be measured accurately and objectively on a large scale, along with peoples psychological attributes and demographic information, more accurate insights into who and what drives plastic bag buying in the real world can be made - and used to more accurately inform future policy decisions. 


\section{Demographic Predictors of Environmental Concern}

Understanding the profile of people who frequently buy plastic bags, in spite of the levy, is important for planning future plastic reduction interventions, legislation, and campaigns. Previous research has shown that people concerned with the environment are more likely to be younger, female, have more money, and a higher education than people less concerned with the environment (Davidson \& Freudenburg, 1996; Hines, Hungerford, \& Tomera, 1987; Kalof, Dietz, Guagnano, \& Stern, 2002; Zelezny, Chua, \& Aldrich, 2000). Unsurprisingly, pro-environmental individuals have been shown to hold positive environmental attitudes (Dunlap, Van Liere, Mertig, \& Jones, 2000), be well informed on the impact of their behaviour (Frick, Kaiser, \& Wilson, 2004), and demonstrate concern over the natural world (Bamberg \& Möser, 2007). However, whether this more general profile of pro-environmental individuals fits specifically those who avoid purchasing single-use plastic bags, has not yet been fully studied.

Observers in Jakovcevic et al. (2014) and Poortinga et al.'s (2016) supermarket observational study, estimated bag buyers' age and gender. The latter found that in England the use of single-use plastic bags decreased from $53 \%$ to $23 \%$ among men, and from $55 \%$ to $20 \%$ among women after the levy. Shoppers estimated to be 18-44 years bought the most plastic bags, whilst older people (estimated to be 65 years or over) bought the least - despite research suggesting older people are less concerned about the environment (Gifford \& Nilsson, 2014). This supports literature finding that younger adults have greater concerns about the environment, but older adults engage in more pro-environmental behaviours (Arcury \& Christianson, 1993; Honnold, 1984; Klineberg, McKeever, \& Rothenbach, 1998). Given this, certain actions or behaviours, such as plastic bag buying, may be less driven by environmental concern, and more by other factors - perhaps frugality (Tapia-Fonllem, Corral-Verdugo, Fraijo-Sing, \& Durón-Ramos, 2013), anti-consumerism (Jackson, 2012), or being motivated to save money (Jakovcevic et al., 2014; Poortinga et al., 2016). 


\section{Personality and Environmental Concerns}

Research has demonstrated that personality can influence people's levels of environmental concern. Early studies found that pro-environmental attitudes were associated with being more liberal (Arbuthnot, 1977) and conscientious (Pettus \& Giles, 1987). Recent research has focused on using the Big Five framework (Costa \& MacCrae, 1992) for measuring personality using the orthogonal trait dimensions of openness to new experiences (intellectual, complex); conscientiousness (dependable, self-disciplined); extraversion (fun, enthusiastic); agreeableness (sympathetic, warm); and neuroticism (anxious, easily upset). Milfont and Sibley (2012) showed that on both an individual level and national level, agreeableness, conscientiousness, and openness to new experiences positively predicted environmental engagement (Borden \& Francis, 1978; Hirsh, 2010; Milfont \& Sibley, 2012). Hirsh and Dolderman (2007) and Hirsh (2010) also found that high agreeableness and openness (strongly), as well as neuroticism and conscientiousness (weakly) positively related to environmental concern. Another study found that agreeableness and conscientiousness were positively related to recycling behaviours (Swami, Chamorro-Premuzic, Snelgar, \& Furnham, 2011). Neuroticism has additionally been found to positively relate to certain aspects of environmental engagement (Wiseman \& Bogner, 2003). Evidence for the role of extraversion, however, has been mixed.

Openness to new experiences has consistently been found to relate to pro-environmental activities in both a community sample and an undergraduate student sample (Fraj \& Martinez, 2006; Markowitz, Goldberg, Ashton, \& Lee, 2012). Markowitz et al. (2012) suggested that high levels of aesthetic appreciation, creativity, and inquisitiveness, rather than altruism, may motivate pro-environmental actions. People high in openness have a greater willingness for change, to break with convention, and experience new ways of doing things (Markowitz et al., 2012). Individuals high in openness are also driven by aesthetic appreciation and intellectual curiosity - both of which can positively influence one's interest in nature and environmentalism (Hartig, Kaiser, \& Bowler, 2001; Hirsh \& Dolderman, 2007). In summary, multiple studies have 
found that different personality traits, namely openness and agreeableness, but also conscientiousness and neuroticism, positively relate to environmental concerns and engagement. However, the extent to which these relationships translate from generalised pro-environmental attitudes and activities to the purchasing of plastic bags in the real world is not known.

Engaging in environmental behaviours involves, not just the motivation or intention to do so, but additionally the self-discipline and belief in the behaviour's impact (Axon, 2017; Van der Linden, Maibach, \& Leiserowitz, 2015). A greater internal locus of control (the degree to which people believe that they have control over the outcome of events in their lives) has been associated with stronger pro-environmental intentions and behaviour in a variety of different countries including both Germany and Japan (Ando, Ohnuma, Blöbaum, Matthies, \& Sugiura, 2010), Australia (Fielding \& Head, 2012) and Canada (Abrahamse, Steg, Gifford, \& Vlek, 2009). This highlights that when studying real world behaviour, it is not just the motivations for that behaviour (i.e. the related beliefs and attitudes) that are important - but also the dispositional traits which affect whether an action is carried out or not. These factors which can increase the likelihood of a motivation to act translating to a behaviour include: self-control, impulsivity, future focus, propensity to plan ahead, and self-efficacy - none of which are explicitly measured using the Big Five.

Future orientation (or having a future time preference) is the tendency to establish goals and to plan strategies for meeting long-term obligations (Corral-Verdugo, Fraijo-Sing, \& Pinheiro, 2006); it is also positively related to sustainable behaviour (Corral-Verdugo et al., 2006; Joireman, Van Lange, \& Van Vugt, 2004; Urien \& Kilbourne, 2011). Frugality or "thriftiness" is defined by being economic with resources, and antagonist to consumerism (Jackson, 2012) and materialism (Goldsmith \& Flynn, 2015). Consumerism is one of the stand out causes of environmental problems (Tapia-Fonllem et al., 2013). As well as frugal people having reduced consumption, frugality affects the type of items purchased, and the methods used for waste disposal. Various studies have demonstrated frugality's relationship with 
pro-environmental behaviours (Gatersleben, Murtagh, \& Abrahamse, 2014; Pepper, Jackson, \& Uzzell, 2011; Tapia-Fonllem et al., 2013). As well as impacting through self-transcendent values such as unity with nature (Todd \& Lawson, 2003), there is also a self-enhancement aspect of frugality which relates to pro-environmental behaviours ambition, self-control, and consumer independence (Goldsmith \& Flynn, 2015). Lastly, low impulsivity (akin to high self-control) relates negatively to the ability to plan ahead (also captured in time preferences), and thus would be expected to negatively relate to those environmental behaviours that require some degree of forethought or planning. Although people higher in openness are also often more impulsive (McCrae, 1993), there is limited literature explicitly on the relationship between the inhibition of impulses and pro-environmental behaviour.

\section{Personality and Plastic Bag Purchasing}

Personality has been shown to predict environmental concerns, engagement and self-reported behaviours. Yet, how this literature translates specifically to bag buying behaviour in the real world is uncertain for the following three reasons:

1) One environmentally conscious behaviour does not always predict another. There is some evidence for environmental behaviour spillover (where one ecological behaviour can lead to another) from plastic bag reduction to other ecological behaviours (Lanzini \& Thøgersen, 2014; Thomas, Poortinga, \& Sautkina, 2016), but it does not always occur (Poortinga et al., 2013; Thøgersen \& Ölander, 2003). It can depend on the type of behaviour and the cost of that behaviour (Lanzini \& Thøgersen, 2014); and in some cases one behaviour could even reduce the propensity to behave environmentally friendly in other areas (Thøgersen \& Ölander, 2003). Ego-depletion theory (Baumeister, Bratslavsky, Muraven, \& Tice, 1998) proposes people have a finite amount of will-power or self control. Once this is used up, people are unable to exert the same level of self control on subsequent, often unrelated tasks or choices. For example: "I spent ages 
sorting the recycling this morning - I didn't have the time or energy to organise bringing a bag for life with me". Thus the factors predicting one environmental behaviour (recycling household waste) may not be predictive of another (bringing a personal shopping bag to the store) - particularly if one behaviour is habitual and the other is not.

2) Limitations exist on the extent to which environmental attitudes and intentions generalise to actual pro-environmental behaviour. For example, Diamantopoulos, Schlegelmilch, Sinkovics, and Bohlen (2003) showed that socio-demographic variables could define consumer profiles for environmental knowledge and attitudes, but were limited for actual behaviour. Environmental knowledge and values have been found to account for only $40 \%$ of the variance in ecological behavioural intentions, which in turn explains just $75 \%$ of the variance in ecological behaviour (Kaiser, Wölfing, \& Fuhrer, 1999). Thus, it is uncertain whether the same personality traits which influence environmental concerns in the literature, predict actual pro-environmental behaviour - specifically the purchasing of plastic bags.

3) Studies which measure self-reported behaviour using questionnaires may be affected by bias (Van de Mortel et al., 2008) or poor memory (Jakovcevic et al., 2014), and may not truly represent behaviour occurring in the real world (Kormos \& Gifford, 2014). Kormos and Gifford (2014) did not find a strong association between self-reported pro-environmental behaviour and objective behavioural measurements. Thus, it cannot be assumed that theories and models constructed on self-reported behaviour, transfer to behaviour measured in the real world.

\section{Measuring Environmental Behaviour in Big Data}

Until recently, objective environmental behaviour has been hard to measure on a large scale, as it has typically involved observing people in the real world without them knowing (Kormos \& Gifford, 2014; Poortinga et al., 2016), gaining peer ratings (which 
can be equally biased/inaccurate) (Chao \& Lam, 2011), or looking at household meter readings (which are often not at the level of the individual) (Fuj, Hennessy, \& Mak, 1985). Field studies allow researchers to study a behaviour from a snapshot in time at a particular location, however they cannot measure the regularity, trends, or patterns in an individual's behaviour. Today, people leave a substantial amount of data in their wake. Smart meters installed into homes, smart appliances, mobile phone records, apps, and transaction records are all sources of data which can now be used to study real world ecological behaviour unobtrusively. Using loyalty cards and personal accounts, researchers can now track and record individual's environmental behavioural patterns over time and space. With permission, this behaviour can additionally be paired to self-reported psychological information. This research exploits such a unique dataset to study the psychological and demographic predictors of frequent plastic bag consumption as it occurs in the real world.

\section{$\operatorname{Aim}$}

In this study, a data driven approach was used to investigate who were continuing to frequently purchase plastic bags in England after the 5p levy was brought in. A dataset consisting of millions of transaction records matched to questionnaires measuring demographics, shopping motivations (including questions on environmental concerns), and individual differences were harnessed to predict and explain the plastic bag buying behaviour. Participants' survey responses were linked with their transaction records measuring retrospectively their plastic bag purchases. Using this sample, the first aim was to produce descriptive statistics on the distribution of bag buying in the UK stores studied, over time and geographical space.

Subsequently, the aim was to build a model to predict frequent plastic bag buyers. As using real world behaviour records didn't allow for the control of confounding variables whilst the behaviour was being measured, extraneous variables such as shopping frequency were statistically controlled for by inputting them into the model. Deviating from the more traditional hypothesis driven approach allowed for an 
inductive exploration of a much larger number of possible explanations. Because of this exploratory approach, particular caution was taken to ensure "p-hacking as procedural overfitting" (Yarkoni \& Westfall, 2017) was not occurring (further discussed in the section Controlling for Multicollinearity, Overfitting, and False Discovery Rates).

\section{Predictions}

A priori predictions were made about which variables were expected to predict frequent plastic bag purchasing. These predictions were based on two different streams of reasoning 1) the characteristics of people who intend to not consume plastic bags (Jakovcevic et al., 2014; Poortinga et al., 2016); and 2) the characteristics influencing people's ability to convert intentions to behaviour (Bamberg \& Möser, 2007; Hines et al., 1987).

Firstly, based on previous findings about the motivations for bag purchasing (Jakovcevic et al., 2014; Poortinga et al., 2016; Sun, Wang, Li, Zhao, \& Fan, 2017), it was expected that a person who was motivated to save money, or had concern for the environment, would intend to bring their own bags to the store instead of purchasing single-use ones. Therefore, it was predicted that frequent bag buyers were more likely to have a higher income, spend more money in store, be less frugal, and have less concern for the environment than infrequent plastic bag buyers.

Secondly, as intending to reduce plastic bag consumption and actually doing so are not the same (Bamberg \& Möser, 2007; Diamantopoulos et al., 2003), many factors can disrupt a motivation or intention converting to behaviour (Kaiser et al., 1999; Sun et al., 2017). Bringing a personal bag to the store is often a required antecedent to refusing a plastic bag at the till, and requires forethought and planning. In other words, if someone was motivated to refuse plastic bags to save money or to help the environment, they could still end up buying bags because they had not adequately planned ahead or had purchased more items than intended on the spur of the moment. Thus, it was predicted that impulsiveness (measured using BAS scales, and self-control) would positively predict regular plastic bag purchasing. 
These hypotheses did not comprise exhaustively the factors investigated. This research also constitutes a bottom-up exploratory investigation into the demographic and psychological variables affecting single use plastic bag consumption. Consequently, this left the current authors open to report and discuss all findings (not just those attached to the hypotheses). Therefore, the data available was also utilised to explore the open ended question: who frequently buys plastic bags?

\section{Method}

\section{Participants}

Online surveys were sent to 80,000 members of the retailer's internal consumer panel. There were 12,968 responses fully completed and matched to participants' purchasing data on their loyalty card. From this data a balanced binary sample was extracted $(N=4,652)$ containing frequent and non frequent bag buyers. See the Procedure section for the full details on how this was done. (For clarity, Table 1 displays the different samples that were utilised in the following analyses).

\section{Materials}

Online Survey. The survey used in this study was a generalised survey, which was designed with the intention of studying, more generally, which psychological factors affect different purchasing behaviours. The survey questions can be categorised into three groups: socio-demographics, psychological characteristics, and shopping behaviours/motivations.

Socio-demographics: The socio-demographic questions comprised of age, gender, marital status, current occupation, annual household income, highest education qualification, (self reported) geographical region, how many people they live with, and how many children they have.

Psychological characteristics: The psychological characteristics measured included time preferences - assessed by the three questions 'Would you rather have $£ 25 / £ 45 / £ 55$ now, or $£ 75$ later?' (Reimers, Maylor, Stewart, \& Chater, 2009), self 
Table 1

The different samples and their uses in the analysis

\begin{tabular}{|c|c|c|c|}
\hline Sample & Use & $\mathbf{N}$ & $\begin{array}{l}\text { Area } \\
\text { covered }\end{array}$ \\
\hline $\begin{array}{l}\text { The store's internal consumer } \\
\text { panel }\end{array}$ & $\begin{array}{l}\text { The pool of participants the sur- } \\
\text { vey was sent to }\end{array}$ & 80,000 & UK \\
\hline $\begin{array}{l}\text { The fully-completed question- } \\
\text { naire responses which were success- } \\
\text { fully linked to respondent's loyalty } \\
\text { card transaction data }\end{array}$ & $\begin{array}{l}\text { Used to produce descriptive } \\
\text { statistics on plastic bag buying }\end{array}$ & 12,968 & UK \\
\hline $\begin{array}{l}\text { The number of identified frequent } \\
\text { plastic bag buyers in the transac- } \\
\text { tion data }\end{array}$ & $\begin{array}{l}\text { Used to create a balanced mod- } \\
\text { elling sample }\end{array}$ & 2,326 & England \\
\hline $\begin{array}{l}\text { The modelling sample created } \\
\text { from the frequent bag buyers being } \\
\text { matched to an equal number of in- } \\
\text { frequent bag buyers }\end{array}$ & $\begin{array}{l}\text { Used to extract the important } \\
\text { predictors of plastic bag buying }\end{array}$ & 4,652 & England \\
\hline $\begin{array}{l}\text { The } 80 \% \text { of the modelling sample } \\
\text { used for training }\end{array}$ & $\begin{array}{l}\text { To train the logistic regression } \\
\text { model }\end{array}$ & 3,722 & England \\
\hline $\begin{array}{l}\text { The } 20 \% \text { of the modelling sample } \\
\text { used for testing }\end{array}$ & $\begin{array}{l}\text { To test the logistic regression } \\
\text { model }\end{array}$ & 930 & England \\
\hline
\end{tabular}

control (Tangney, Boone, \& Baumeister, 2018), impulsiveness using the Behavioural Activation Scales (BAS) (Carver \& White, 1994) measuring reward responsiveness (BAS-RR), drive (BAS-D) and fun seeking (BAS-FS), and the Ten Item Personality Inventory (TIPI) version of the Big Five (Gosling, Rentfrow, \& Swann Jr, 2003)

Shopping behaviours and motivations: The items measuring shopping motivations included an eight item frugality measure (Lastovicka, Bettencourt, Hughner, \& Kuntze, 1999), a shopping impulsivity scale (Rook \& Fisher, 1995), and a series of questions about different shopping motivations which included two questions on environmental concerns: 'Environmental considerations affect the products that I purchase'; and 'I am concerned about climate change (also known as global warming)' ${ }^{2}$. A correlation

\footnotetext{
${ }^{1}$ The TIPI measure was used as the final generalised questionnaire asked a large number of questions, and an extended measure of the Big Five would have significantly increased the time it took to complete the questionnaire, and thus the likelihood of participants dropping out.

${ }^{2}$ It is worth noting here that the questions and measures used in this study were not designed for the sole purpose of understanding plastic bag purchasing, and in this way could be considered secondary
} 
matrix of the interrelationships between measures can be found in Figure 3, and a link to a full copy of the survey sent to participants can be found in Appendix A.

Transaction Data. The study utilised, under informed consent, historical transaction (purchase) records for the survey respondent from a high-street health and beauty retailer, recorded as part of the retailer's loyalty card scheme. Permission to acess the data was provided explicitly as part of the survey. Before the individual's purchasing data was analysed, it was pseudo-anonymized to link the questionnaire responses with the transaction data prior to full anonymization. No incentives were offered for taking part in the study. This study received full ethical approval from the university.

In order to consider repeat purchasing behaviour of single use plastic bags, data was extracted for a period of 9 months following the introduction of the $5 p$ levy in England on the 5th of October 2015. Over this period the data included the shop location, all participants' purchases and their value (grouped by transaction). Purchases of single use plastic bags are explicitly recorded in this data.

Feature Engineering. The survey data and the associated 9 months of transaction data formed the available features for the study. Focusing on understanding the underlying motivations of consumers who frequently purchase single use plastic bags, the majority of the independent variables (input features) were drawn from the survey data with only a single input feature (average monthly spending) included from the transaction data. The dependent variable was coded from the objective transaction data.

Engineering the dependent variable: Plastic bag sales were coded in the data for shoppers in England after the 5p levy was brought into action on the 5th October 2015. This meant that every time a bag was purchased using a loyalty card information on that transaction was recorded, including a description of the type of bag purchased. Although bags for life can also threaten our marine environments (DEFRA, 2018b), at this time they were seen as the pro-environmental choice (Poortinga et al., 2016). Bags data. 
for life were therefore not included, as the analysis wanted to capture the characteristics of those individuals who's behaviour was least impacted by the $5 \mathrm{p}$ levy intervention. Therefore, the bags in this study are either the single-use or medium-strength plastic bags for which the levy applies.

The total quantity of transaction data which was linked to the survey participants (with complete questionnaires) consisted of 1,284,825 distinct transactions from 1,222 different stores by 12,968 people across the UK. The total number of plastic bags bought by this sample was 20,504. Using this data, the percentage of times each person bought a plastic bag in England (when the data suggested they had bought enough items to warrant needing one) was calculated. This was done by only analysing the shopping trips where either one the two following conditions were satisfied: 1) they had 3 or more items in their 'basket' (used here to denote the items bought in one transaction, not a physical basket), or 2) they had a basket volume of over 2,225 $\mathrm{ml}$ (approximately an 8th of the total volume of a standard carrier bag volume (18 litres)).

By only analysing these higher-quantity baskets, baskets where a customer buys only a couple of items that could fit in their pocket/hands are not included in the analysis. Therefore, the measure of bag buying used here is the proportion of times a person makes a single-use plastic bag purchase when a bag was deemed to be required to carry their shopping. If a bag was not brought when the conditions for needing one were satisfied, it was inferred that they either bought their own bag to the store, made an effort to carry multiple items or a large volume of items by hand, or bought a bag for life $^{3}$.

Independent Variable Encoding: Before being entered into the logistic regression model, categorical variables were dummy coded, giving a total of 92 predictors. For income (which was not strictly an ordinal variable due to the 'prefer not to say' category) the lowest income category 'Less than $£ 25,000$ ' was removed as the reference class. For the rest of the variables the most frequent class was the reference class, in order to compare the effects of smaller groups to the larger normative group. For

\footnotetext{
${ }^{3}$ Of course other circumstances may have arisen that cannot be known about, such as buying a single-use plastic bag from another high street retailer prior to shopping at the store in question
} 
loyalty card use the reference group was 'every time', for shopping frequency 'once a fortnight', for the people you are living with this was 'partner', for marital status 'married', for occupation 'intermediate manager/professional/administrative', for highest qualification 'bachelors'degree, and for region the most common was 'Yorkshire'.

Although shopping frequency was being controlled for by engineering the outcome variable using the percentage of times a person bought a bag (when one was required), it was further controlled for by including self reported shopping frequency, loyalty card use, and average monthly spend (calculated from the transaction data) as features in the model. To aid interpretation, all continuous variables were mean centred and standardised before being input into the model. The descriptives of the continuous independent variables from the balanced modelling sample can be viewed in Table 2 . The full list of features used are available in the full results table in Appendix C.

\section{Procedure}

Using transaction data as a measure of behaviour, as well as an inductive exploratory approach, meant that some additional procedural steps were required. This section describes first how a smaller sub-sample was extracted for modelling, containing an equal number of frequent and non frequent bag buyers. It then describes how, because of the large number of variables being investigated, multicollinearity, overfitting, and false discovery rates (FDR) were controlled for.

Creating a Balanced Modelling Sub-sample. From the whole surveyed sample $(N=12,968) 56 \%$ had never bought a single-use plastic bag. Of those who had bought a bag at least once, the proportion of purchases that included a single-use bag, when they had bought enough items/volume of items to suffice needing one (see section on engineering the dependent variable) is plotted in Figure 1. Only 1,014 people had bought a bag on $50 \%$ or more of their bag-warranting visits. Because of the non-normal distribution (positive-skew) of bag buying behaviour, and the fact that this investigation was particularly interested in the sub-group of individuals who frequently bought plastic bags, rather than predict the percentage of trips a bag was bought, a 
binary outcome variable was created to divide people into frequent and infrequent bag buyers. For this, a cut-off percentage value was selected that weighed up a) extracting a sample of people who really were repeatedly buying plastic bags, with b) the size of the sample attained (i.e. avoiding throwing too much data away). It was decided that because of the strong positive skew in Figure 1, the cut-off of buying a bag $25 \%$ or more of the bag-warranting shopping trips was sufficient to separate frequent bag buyers from less frequent bag buyers (the norm in the data).

Therefore, individuals who bought bags on $25 \%$ or more occasions, and who had fully completed the questionnaire, made up the positive class in the modelling sub-sample $(N=2,326)$. An equal number of infrequent bag buyers (people who bought a plastic bag with less than $25 \%$ of their bag warranting visits) were then randomly sampled - producing the balanced modelling sample of 4,652. The descriptives of the continuous independent variables from the balanced modelling sample are shown in Table 2.

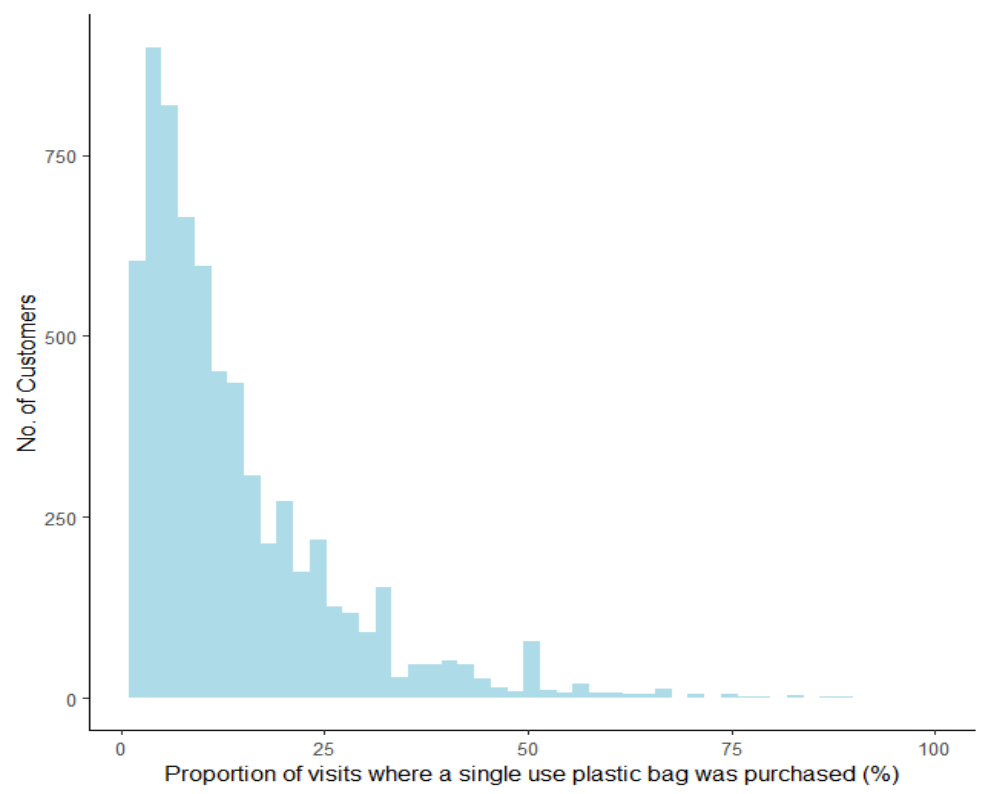

Figure 1. A graph to show the distribution of plastic bag purchases when enough items or volume of items to warrant needing one were purchased. Those who never purchased a bag $(0 \%)(N=8,546)$ are not represented in this graph. The cut-off of $25 \%$ or more determined the frequent bag buyers.

\section{Controlling for Multicollinearity, Overfitting, and False Discovery}

Rates. Multicollinearity: As this analysis involved interpreting the standardised $\beta$ 
values (which are affected by multicollinearity) in the context of predictive variable importance, the degree of collinearity between variables was checked using the Variable Inflation Factor (VIF). Four variables had a VIF above the chosen threshold of 2.5

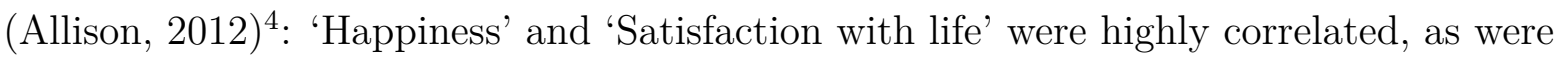
'Living on own', and 'Marital Status: Single'. To ensure the multicollinearity did not interfere with the variable importance measure, Satisfaction ad Happiness were combined into a single well-being variable (Diener, Lucas, Oishi, et al., 2002), and 'living on own' was removed. The model was re-fitted to check the VIF levels and all were subsequently below the 2.5 threshold ('Well-being' = 1.45, 'Marital Status: Single' $=1.64)$.

Overfitting: Notably the decision to include a large number of variables in the model's selection pool brings with it an increased risk of over-fitting. Without care, a sample fit statistic can be produced that is unrepresentative of the general population. This issue is known as 'procedural overfitting', (Yarkoni \& Westfall, 2017) and an inadvertent form of p-hacking. Such dangers can be mitigated against through the rigorous use of cross-validation and, for logistic regression, the use of regularisation parameters (Ng, 2004), and/or recursive feature elimination (Pedregosa et al., 2011). The key to the cross-validation approach well established in computational science and of growing use in the traditionally inferential statistical sciences (Dahl, Grotle, Benth, \& Natvig, 2008; Yarkoni \& Westfall, 2017) lies in the iterative use of hold-out data partitions to ensure that the selected model specification (in this case, the independent features and meta-parameters controlling regularisation) is the one that optimally generalises to out-of-sample data.

First, 20\% $(N=930)$ of the sample were excluded at random, and this data was set aside as the "unseen" test data for evaluating the final model's performance. The remaining $80 \%(N=3,722)$ of the data were used within a $\mathrm{k}$-fold cross validation procedure (where $\mathrm{K}=5$ (Bishop, 2006)) to repeatedly train and evaluate (1) multiple different logistic regression variants based on different levels of regularisation via a

\footnotetext{
${ }^{4}$ This threshold, in the context of the large dataset, is particularly stringent (O'brien, 2007).
} 
systematic search over a range of parameterisations (grid search, see Appendix B) and (2) recursive feature elimination.

K-fold cross validation was used to recycle data for training and testing within the $80 \%$ training sample (see Figure 2). The data was divided into $\mathrm{K}$ equal samples (folds). One fold becomes the test set, and the remaining folds are the training data. This process is repeated, computing the performance statistic of interest for each of the hold-out folds until each fold has been the test data (K times). The average of the performance statistic across all folds is then calculated. To evaluate the performance of different (regularisation) parameters the Mean Absolute Error (MAE) was used. To select the final features, the Area Under Curve (AUC) score was measured within the recursive feature elimination procedure (using cross validation). This procedure identified just one variable which could be removed without affecting the AUC score, indicating its redundancy. This variable was Duration, which measured the time it took the person to complete the online questionnaire. Removing Duration left us with a total of 92 predictor variables, which were all entered into the final regularised regression model.

1.

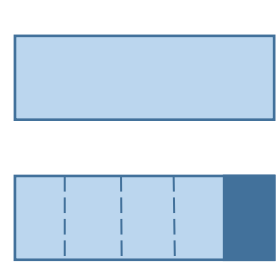

3.

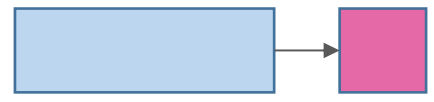

4.

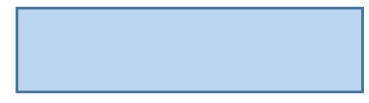

The sample $(\mathrm{N}=4,652)$ was split into a $20 \%$ test sample $(\mathrm{N}=930)$ and an $80 \%$ training sample $(\mathrm{N}=3,722)$.

5-fold cross validation was performed on the training data to optimise the model's meta-parameters

The performance of the optimised model was then tested on the held out sample.

The model, using the optimised meta-parameters, was fitted to $100 \%$ of the data to extract variable importance information.

Figure 2. The cross-validation paradigm used in this study to prevent $p$-hacking

Once the final logistic regression model was selected, the model's performance was tested on the unseen (20\%) test data. The model's accuracy was evaluated using the $F_{1}$ score. The $F_{1}$ score combines both recall (the percentage of total relevant results 
correctly classified) and precision (the percentage of correctly classified results in the positive/relevant class) to indicate performance whilst balancing type 1 and type 2 error. Testing the model on data that is unseen by the algorithm provides a score indicating how the model is expected to generalise. This estimation is generally much more conservative than performance measures calculated by fitting a model to $100 \%$ of the data (Yarkoni \& Westfall, 2017).

As a result of the model selection procedure above, and evaluating the model performance on how well it generalises to new data, p-hacking as procedural overfitting is avoided. At this point, the methodology returns to a more traditional analysis when investigating the significance of the predictive variables using standardised $\beta$ values, and controlling for the likelihood of some variables being significant by chance using the Benjamin-Hochberg false discovery procedure ${ }^{5}$.

False Discovery Rates: The final step of the analysis was to extract the significant predictive variables of frequent bag buying behaviour from the model. Due to having a large number of independent variables, the likelihood of some variables being significant by chance was controlled for using the Benjamini-Hochberg false discovery procedure with a $q$-value of 0.05 (Benjamini \& Hochberg, 1995). The $q$-value is the expected proportion of false positives among all features as or more extreme than the observed one. Therefore a $q$-value threshold of 0.05 yields a FDR of $5 \%$ among all features called significant $^{6}$. By only reporting variables which passed the Benjamini-Hochberg test, the likelihood of type 2 error was increased (missing a positive result) in order to reduce the likelihood of a type 1 error (false discovery) (Benjamini \& Hochberg, 1995). Thus, as well as tuning meta-parameters and using out of sample testing to increase the generalisability of the model, this conservative approach to analysing the statistical significance of the predictive variables helped ensure the replicability of the findings.

\footnotetext{
${ }^{5}$ It is noted that the use of cross-validation can theoretically be extended to address issues of p-hacking within variable importance calculations, however, it's use is not widespread and as such more traditional approaches were preferred for this work.

${ }^{6}$ This is not to be confused with a $p$-value threshold (alpha) of 0.05 , which yields a false positive rate (FPR) of $5 \%$ among all truly null features.
} 


\section{Results}

\section{Descriptive Statistics}

Before predicting frequent bag buying using the modelling sample, descriptive statistics were first produced on the whole sample $(N=12,968)$ to investigate the distribution of bag sales over time and geographic space. Overall, a very small sample of people were frequently buying plastic bags, with $56 \%$ of the full sample having not bought a single-use plastic bag at all, and just $18 \%$ being characterised as frequent bag buyers. The descriptive statistics for the continuous independent variables can be found in Table 2. The weekly plastic bag sales in England (per 1,000 items) in the 9 months following the levy can be viewed in Figure 5. Across the UK, more bags per 1,000 items were bought during the Christmas festive period (week 50-53: 7th December to the 3rd January). In the 9 months proceeding the levy start date (15th October 2015) plastic bags bought per week per 1,000 items in England show a significant linear decrease $\left(t(40)=-3.55, p=0.001, R^{2}=0.24\right)$. However, as the data on plastic bag consumption prior to the levy was not available, or a full years data after the levy, it cannot be determined whether this decrease in bags is related to the levy, or an annual seasonal trend (more bags bought around Christmas and fewer in the summer). 
Table 2

Descriptive statistics for the continuous independent variables in the modelling sample

\begin{tabular}{lcccc}
\hline \hline & Min & Max & Mean & SD \\
\hline Average Monthly Spend (£) & 2.67 & 380.44 & 42.40 & 27.35 \\
Age (years) & 17 & 95 & 50 & 15 \\
Extroversion & 1 & 7 & 4.05 & 1.55 \\
Agreeableness & 1 & 7 & 5.51 & 1.12 \\
Openness & 1 & 7 & 4.85 & 1.19 \\
Conscientiousness & 1 & 7 & 5.81 & 1.10 \\
Emotional Stability & 1 & 7 & 4.69 & 1.47 \\
Well-being & 0 & 10 & 7.18 & 1.89 \\
Self-control & 1.15 & 5 & 3.31 & 0.66 \\
Frugality & 1 & 6 & 4.56 & 0.88 \\
Shopping Impulsivity & 1.11 & 5.11 & 2.73 & 0.86 \\
BAS-RR & 1.20 & 4 & 3.22 & 0.46 \\
BAS-FS & 1 & 4 & 2.77 & 0.53 \\
BAS-D & 1 & 4 & 2.44 & 0.64 \\
SM1: I would rather stick to a brand I usually buy... & 1 & 7 & 4.51 & 1.57 \\
SM2: I enjoy taking chances in buying unfamiliar brands... & 1 & 7 & 3.97 & 1.50 \\
SM3: If I like a brand I rarely switch... & 1 & 7 & 4.65 & 1.54 \\
SM4: I would not mind paying more for high quality... & 1 & 7 & 5.43 & 1.23 \\
SM5: I only buy products I trust. & 1 & 7 & 5.26 & 1.40 \\
SM6: Product quality is extremely important... & 1 & 7 & 6.12 & 1.05 \\
SM7: I am pleased about the way I look... & 1 & 7 & 4.32 & 1.54 \\
SM8: When I feel good about my looks, I am happier... & 1 & 7 & 5.78 & 1.19 \\
SM9: When I see a mirror, I "check myself out"... & 1 & 7 & 3.90 & 1.75 \\
SM10: Environmental considerations affect the products that & & & & \\
SM11: I am concerned about climate change... & 1 & 7 & 4.43 & 1.52 \\
\hline \hline
\end{tabular}

Note: SM refers to Shopping Motivation, so that SM1 refers to the first item on the Shopping motivation questionnaire (and so on). For the full SM items see Appendix C. SD = Standard Deviation. 

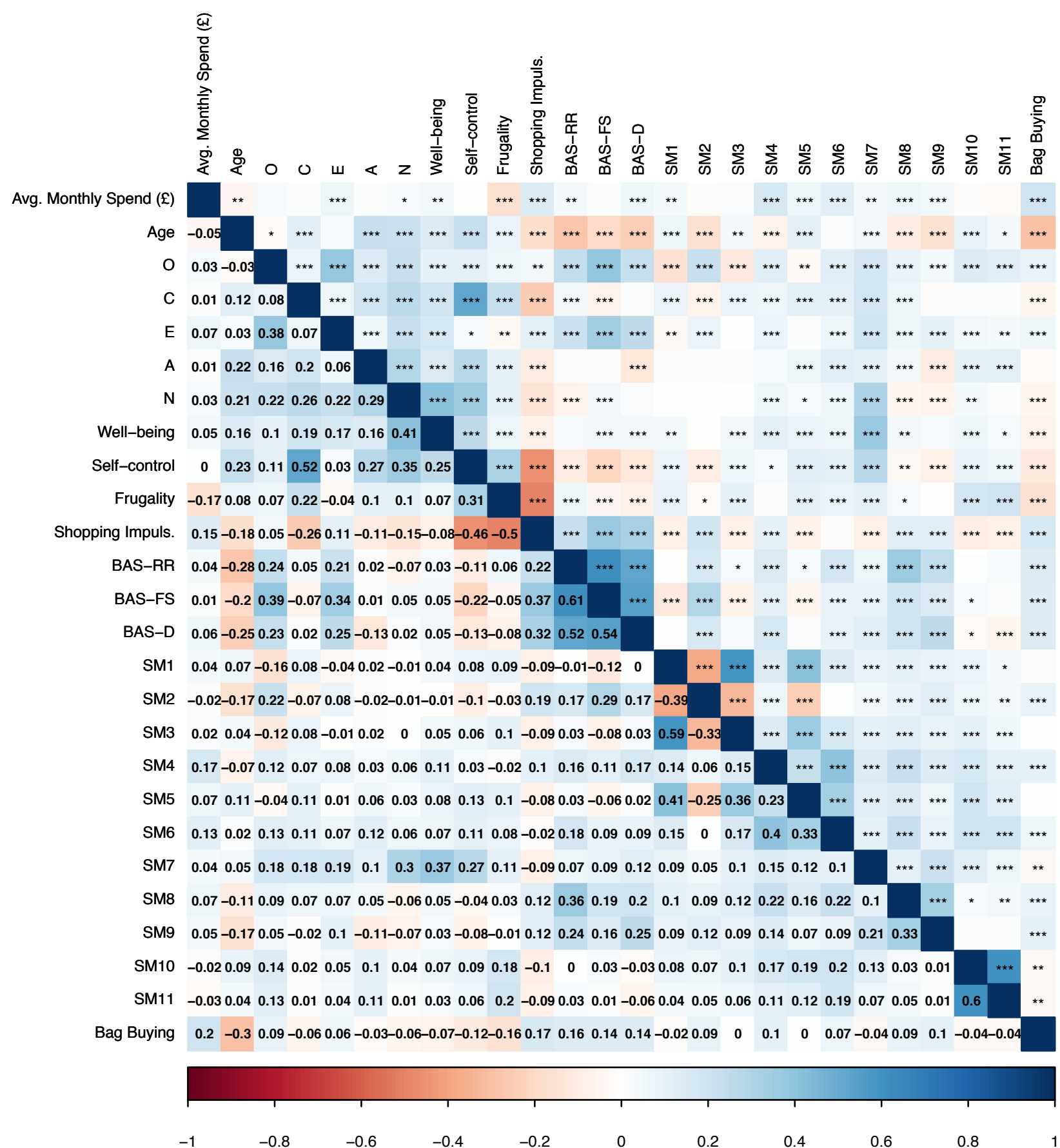

Figure 3. Correlation matrix of the continuous independent variables and the dependent variable in the modelling sample. 'Bag Buying' where $1=$ frequent bag purchasing and $0=$ infrequent. The lower section of the matrix displays the Pearson $\mathrm{r}$ correlation coefficients. The upper section shows the significance levels where ${ }^{*} \mathrm{p}<0.05 ;{ }^{* *} \mathrm{p}<0.01$; ${ }^{* * *} \mathrm{p}<0.001$. SM1: 'I would rather stick to a brand I usually buy..., SM2: 'I enjoy taking chances in buying unfamiliar brands...', SM3: 'If I like a brand I rarely switch..., SM4: 'I would not mind paying more for high quality...', SM5: 'I only buy products I trust.', SM6: 'Product quality is extremely important to me.', SM7: 'I am pleased about the way I look...', 'SM8: When I feel good about my looks, I am happier..., SM9: 'When I see a mirror, I "check myself out"...', SM10: 'Environmental considerations affect the products that I purchase.', SM11: 'I am concerned about climate change...' 

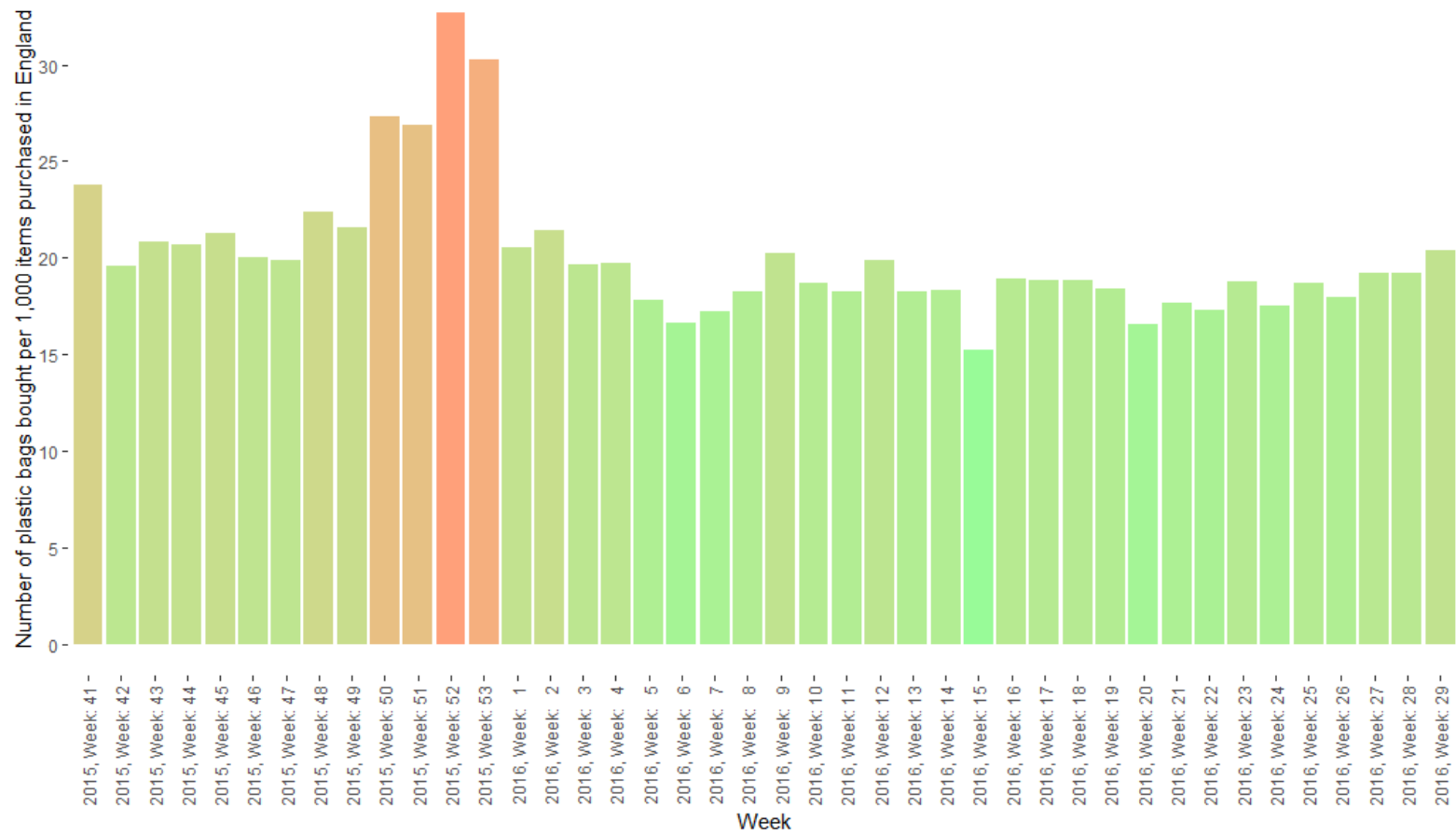

Figure 4. A graph to show the number of sales of single use plastic bags per 1000 items purchased in England each week by the survey sample $(\mathrm{N}=12,968)$. Week 44 is the week of Halloween, week 48 the week black Friday occurred, and week 52 is the week of Christmas.

The distribution of plastic bag sales were then compared across different regions within the UK (see Figure 5). Northern Ireland had the highest percentage of bags per 1,000 items bought, followed by Scotland, Wales, and regions of North West England. Regions in the South West of England (Cornwall and Devon) people had bought the lowest number of bags per items. An ANOVA showed that these differences in the number of plastic bags purchased by region were significant $\left(F(11,1210)=8.8, p<0.001, \eta_{p}^{2}=0.07\right)$.

At a country level, bonferroni corrected t-tests showed that in England significantly fewer plastic bags were bought per 1,000 items than in Northern Ireland $(t(36)=-3.23, p<0.001, d=0.85)$, Scotland $(t(115)=-4.03, p<0.001, d=0.65)$ and Wales $(t(62)=-3.00, p<0.001, d=0.87)$ but there were no statistically significant differences between the latter three countries. A multi-level model with random intercepts for store type showed that the significant country-level differences in plastic bag consumption remained when the types of store (i.e. chemist, high street (small or large), convenience, 
or travel store) were accounted for $(F(3,1211)=26.40, p<0.001)$.

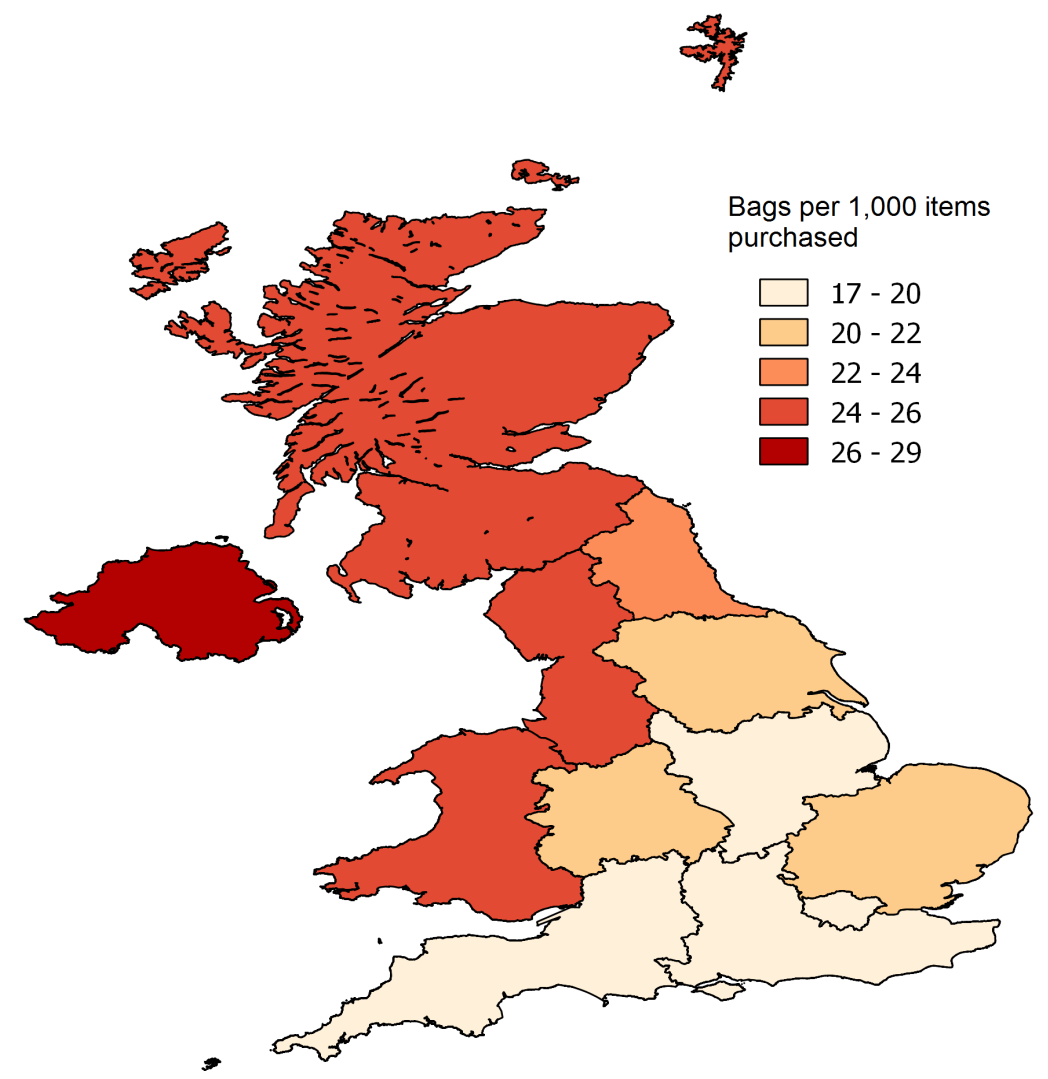

Figure 5. A map of the UK showing in each region the standardised percentage of bags sold by the retailer per number of transactions in that region. The standardised bag sales were calculated using the full survey sample of 12,968 people.

\section{Prediction Results}

To investigate who frequently bought plastic bags, a logistic regression model was optimised on training data (see Methods section) to predict frequent and infrequent bag buyers in an unseen test dataset. The logistic regression, when tested on the $20 \%$ balanced unseen data $(N=930)$, classified frequent bag buyers and infrequent bag buyers correctly in $67 \%$ of cases $\left(F_{1}\right.$ score $\left.=0.67\right)$. The model was equally good at classifying frequent and infrequent bag buyers (see Figure 6 for the confusion matrix).

When the model was fitted to the whole sample of data to extract variable importance, the McFadden pseudo $\mathrm{R}^{2}$ value (McFadden et al., 1973) for the model was 0.13. Twenty-five variables were significant predictors of bag buying frequency with a threshold of $p<0.05$. After the Benjamini-Hochberg false discovery procedure $(q=0.05$, 
see Methods section) 10 of those remained significant predictors of frequent bag buying: Age (negatively), Average monthly spend (positively), Gender (Male positively), Frugality (negatively), Openness (positively), the question 'I am pleased with the way I look', and the self reported "home" geographical regions 'West Midlands', 'North West', 'North East', and 'East Anglia'. The 10 predictors and their direct correlations with the dependent variable, standardised beta regression coefficients with $95 \%$ confidence intervals, and $p$-values can all be viewed in Table 3. Notably the two questions measuring environmental concerns were not significant, and neither were impulsivity measures. A full output of all the logistic regression features, their beta coefficients, and $p$-values can be found in Appendix $C$.

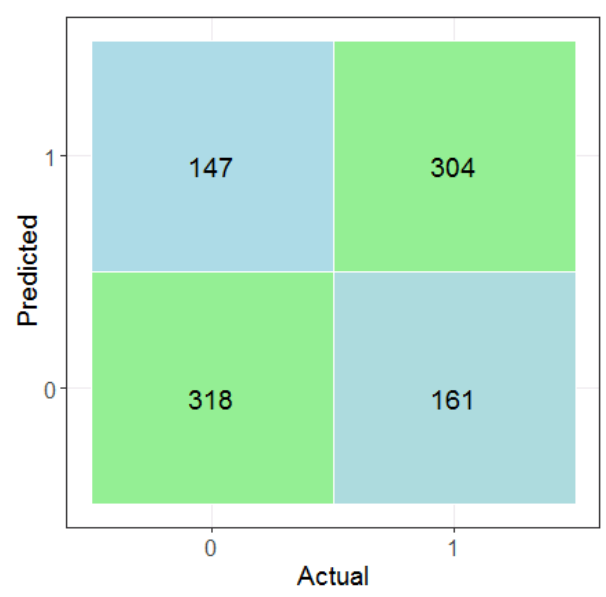

Figure 6 . Confusion matrix for the logistic regression predicting the test data. $0=$ infrequent bag buyers, $1=$ frequent bag buyers.

\section{Discussion}

Until now very little has been known about the type of people who regularly buy plastic bags. This study used a mass transaction dataset linked to a personality questionnaire to profile the psychological and demographic predictors of regular plastic bag buying. As predicted, infrequent single-use plastic bag buyers were more frugal and spent less money in store, suggesting shoppers are motivated to go bag-free by saving money. Interestingly, and contrary to hypotheses, climate change concern did not predict single-use plastic bag purchasing - suggesting concern for the environment was not motivating the behaviour. 
Table 3

Logistic regression model predicting frequent plastic bag buyers

\begin{tabular}{lccc}
\hline & \multicolumn{3}{c}{ Frequent plastic bag buyers } \\
\cline { 2 - 4 } & $\begin{array}{c}\text { pearson } \\
r\end{array}$ & $\begin{array}{c}\beta \text { coefficients } \\
\text { and } 95 \% \text { CIs }\end{array}$ & $\begin{array}{c}\text { Odds } \\
\text { Ratio }\end{array}$ \\
\hline Age (years) & -0.30 & $-0.60^{* * *}[-0.70,-0.50]$ & 0.96 \\
Average monthly spend (£) & 0.20 & $0.43^{* * *}[0.35,0.51]$ & 1.02 \\
Gender: Male & & $0.21^{* * *}[0.15,0.28]$ & 2.15 \\
Frugality & -0.16 & $-0.21^{* * *}[-0.29,-0.13]$ & 0.78 \\
Openness & 0.09 & $0.14^{* * *}[0.06,0.22]$ & 1.12 \\
Region: West Midlands & & $0.12^{* *}[0.05,0.19]$ & 1.68 \\
SM7: I am pleased about the way I look & -0.04 & $-0.13^{* *}[-0.20,-0.05]$ & 0.92 \\
Region: North West & & $0.12^{* *}[0.04,0.19]$ & 1.51 \\
Region: North East & & $0.11^{* *}[0.04,0.18]$ & 1.60 \\
Region: East Anglia & & $0.10^{* *}[0.03,0.17]$ & 1.68 \\
\hline \hline
\end{tabular}

Note: Significance levels are ${ }^{*} p<0.05 ;{ }^{* *} p<0.01 ;{ }^{* * *} p<0.001$. The coefficients reported in the table are the standardised $\beta$ coefficients with standardised $95 \%$ confidence intervals. The pearson $r$ squared is provided to show the correlation with the outcome variable for continuous independent variables only. The significant variables are ranked by the size of the absolute $\beta$ coefficients. The beta coefficient represents the degree of change in the dependant variable for every 1-unit (standard deviation) of change in the predictor variable.

It was additionally anticipated that a lack of self-control or heightened impulsiveness would play a role in people forgetting to take personal bags to the store and hence would positively predict single use plastic bag purchasing. This was not the case, however high openness did. Overall the results highlight the differences between predicting environmental concerns and predicting a specific environmental behaviour in the real world.

\section{Descriptives Discussion}

Overall a very small sample of people were frequently buying plastic bags, with over half of the full survey sample having not bought a single-use plastic bag in the 9 months after the levy. This is very encouraging, and corroborates evidence from DEFRA (2018b) that the levy is working to reduce single use plastic bag consumption. Statistics on plastic bag use concentrate on bags bought from the top 7 supermarket chains (DEFRA, 2018b) and less is known about the bag sales from non-supermarket retailers. The findings suggest that the success of the levy in reducing single-use plastic 
bags in supermarkets has extended to high-street health and beauty retailers.

In the 9 months following the levy, the sales of plastic bags per items bought significantly decreased. However, because the data did not extend to after the 9 months it could not be determined whether the trend was levy related or a seasonal bag purchasing trend (more around Christmas, and less in the summer). Consumers may be buying more plastic bags around Christmas for practical reasons, for example, they don't want others to see their gift purchases, to protect purchases from the weather, or it might make returns easier. Alternatively, the increase around Christmas could reflect a change in customers' psychological states. For example, greater present buying may lead to a greater focus on materialism, which could drive high consumption high throw-away behaviours. This is supported by average monthly spend being the strongest predictor after age of regular plastic bag consumption in the logistic regression model. Alternatively, people may be more stressed over the festive period, leading to greater disorganisation, and less planning of shopping trips. Overall, these findings suggest that plastic bag reduction campaigns targeted during the festive period could have considerably more impact than those targeted in the summer months.

The geographic distribution of the bag sales in the full sample, per number of items bought, showed evidence of a North-South divide in the UK. People in Northern Ireland, Scotland, the North West, and Wales purchase more bags than people in Southern regions. At a country level, England significantly had less bag sales per one thousand items than Northern Ireland, Scotland, and Wales. This shows the short-term effectiveness of the levy as an intervention in England, but highlights that an indifference to the levy in the other countries, which introduced the levy earlier, could have occurred. Wales introduced the 5p levy in 2011, then Northern Ireland and Scotland followed in 2013 and (October) 2014 respectively. National statistics showed a large decrease in bag sales in these countries initially post-levy (DAERA, 2018; Scottish Government, 2015; Welsh Government, 2016), but after a number of years the levels are significantly higher than that in England recently post-levy.

Some variants exist in the levies across the different UK countries in terms of 
price, and also the type of bag the charges applied for. England, for example, was the only country where only plastic bags were charged, whilst for the other countries the levy applied to paper bags as well (Thomas et al., 2019). Still, it is possible the results indicate that the short term effects of the levy are much greater than the long term effects. In (southern) Ireland a plastic bag levy was introduced in 2002, and initially bag use reduced by $94 \%$ (Convery, McDonnell, \& Ferreira, 2007). However, after the initial drop plastic bag use started to rise again (Clarke, 2014; Xanthos \& Walker, 2017). The data may be showing some indication of an increased indifference to bag charges in Wales, Northern Ireland, and even Scotland just a year later.

\section{Demographic Predictors}

The logistic regression model used age as the greatest predictor, where younger people were more likely to be frequent single-use plastic bag buyers - replicating Poortinga et al. (2016)'s findings. This is contrary to the literature that finds younger people care more about the environment (Hines et al., 1987), but in line with the findings that suggest younger people are less likely to participate in pro-environmental behaviours (Arcury \& Christianson, 1993; Honnold, 1984; Klineberg et al., 1998). It is suspected that the results can be explained by people who are older being better at planning ahead and bringing personal bags to the store. This corroborates previous research (Poortinga et al., 2016) suggesting that future plastic bag reduction efforts should concentrate on targeting younger people with interventions or plastic bag alternatives to make it easier to make a plastic free choice at the till. An increased focus on targeting young people and children will also help to ensure longer term societal change, as these are our future actors. Further, children can be important social influences on their peers, parents, and community (Hartley, Thompson, \& Pahl, 2015).

It was expected that higher income would predict frequent plastic bag buying, as people with a lower income would be more motivated to save money. This was not the case, but it was found that spending more money in store positively predicted bag purchasing. This stands against literature suggesting that pro-environmentalists tend to 
be middle or upper-middle class individuals (Balderjahn, 1988; Howard, Delgado, Miller, \& Gubbins, 1993) and suggests the mechanism behind bag buying may be more dispositional (i.e. wanting to be frugal, or less materialistic/consumerist) than circumstantial (needing to save money). This may change however, as the government plan to increase the levy in price (DEFRA, 2018a), and retailers are already placing their own higher charges on plastic bags.

\section{Environmental Concern}

The ecological motivations for bag buying behaviour were evaluated using two questions: one on consumer environmental considerations, and the other measuring climate change concern. Contrary to hypotheses neither questionnaire items related to bag buying behaviour. This indicates a disconnect between peoples' concerns on climate change and the act of buying a plastic bag. Plastic consumption, until recently, has been viewed in the public sphere as a separate issue (one of littering) to that of greenhouse gasses causing global temperatures to rise (Royer, Ferron, Wilson, \& Karl, 2018). Recent research has now connected the two environmental issues revealing that as light breaks down plastic, two of the most problematic greenhouse gases, methane and ethylene, are released (Royer et al., 2018). In research by Sun et al. (2017) it was stated as "obvious" that environmental concern predicts willingness to use plastic bags. However, the findings suggest that the relationship between environmental concerns and plastic bag consumption is more complex.

The questionnaire items used to measure environmental concerns were not selected for the sole purpose of studying plastic bag purchasing, and thus may not fully capture what it means to care about the environment (or not). In spite of this, it is significant that general climate change concern and a pro-environmental behaviour (reducing plastic bag waste) show no statistically significant relationship. This particularly highlights the dissociation between measuring environmental concerns and actual pro-environmental behaviour in the real world. Education on the relationship between plastic bag consumption and climate change could help reduce the number of 
plastic bags being bought - as those concerned about global warming will be more aware of the detrimental effects, subsequently helping to fuel motivation to stop purchasing plastic bags.

\section{Psychological Predictors}

As hypothesised, frugality negatively predicted bag buying behaviour - reflecting economic and ecological motivations. Frugality, often seen as the antithesis of consumerism and materialism (Jackson, 2012), also reflects the values of an older generation/past-era of "make do and mend", pre-dating the throw-away culture of today's society. Honnold (1984) demonstrated that the miss-match between younger people showing more environmental concerns and older people partaking more in pro-environmental activities could be explained by era differences in society. This suggests that placing more value on thriftiness once again in society, particularly for the younger generations, could improve adherence to single-use plastic reduction strategies.

Our final prediction was that trait impulsivity (measured using BAS and self-control scales) would predict plastic bag consumption - where the more impulsive (and less self-control someone has) the more likely they would be to frequently buy plastic bags. It was reasoned that the propensity to plan ahead (synonymous with low impulsivity) is important for bringing personal bags to the store, and thus refusing plastic bags at the till. However, none of impulsivity, future focus, or self control indicators were significant in the prediction model. This may be in part because the frugality measure used in this study encapsulated forward thinking and planning (as well as thriftiness). For example, the question 'there are things I resist buying today so I can save for tomorrow' is tapping into immediate impulse control for a greater reward in the future. People who orient their thoughts towards the future are more likely to plan their shopping trips, increasing the likelihood of bringing personal bags to the store. Furthermore, holding the future in greater esteem than the present may lead future focused people to consider the effect of today's actions on tomorrow's environment, in line with theory of psychological distance (Spence, Poortinga, \& Pidgeon, 2012). 
Despite the literature finding that traits openness, conscientiousness, agreeableness, and neuroticism significantly predict environmental concern and engagement (Hirsh, 2010; Milfont \& Sibley, 2012), the results showed that only openness significantly predicted plastic bag buying. The results showed that people who are open to new experiences are more likely to frequently buy plastic bags - the opposite to what was expected from the literature (which finds individuals high in openness to be more concerned and engaged with the environment). This difference could be either because there is something uniquely different about plastic bag buying and it's drivers, compared to other ecological activities; or because this study measured a real world behaviour, and this is somewhat removed from self-reported behaviours and measures of environmental concern/engagement (Kormos \& Gifford, 2014). As environmental concerns themselves were not predictive of the bag buying behaviour, it is imagined that the latter is a more likely explanation. This has implications for policies which are informed by research using self-reported behavioural measures.

It was suspected that the facets of openness most predictive of bag buying are those tapping into impulsiveness, rather than intellect and liberalism (McCrae, 1993). This is supported by the positive correlation between openness and BAS in the data (see Figure 3). However, facet level openness was not measured, and it is recognised that there are limitations in using the low resolution measure of the big five (TIPI) (Gosling et al., 2003). Thus, this is highlighted as an area which would benefit from further investigation. Despite this limitation, the results suggest that strategies for reducing plastic bag purchasing could benefit from making reduced consumption novel, exciting, cutting-edge, and of great importance - appealing to shoppers high in openness.

An unexpected finding was that frequent bag buyers rated themselves as being less pleased with how they look (an item on the shopping motivation scale - see Appendix A for a full set of the questions) compared with infrequent bag buyers. In the data, people who were not happy with how they look had lower well-being, lower self-control, and were also more neurotic (see the correlations in Figure 3). Interestingly, this single question about appearance appears to capture a broader sense 
of dissatisfaction with oneself and a lack of self-efficacy (which has been shown to be important for engaging in environmental behaviours (Axon, 2017; Van der Linden et al., 2015)). This questionnaire item being a significant predictor of bag buying was an interesting surprise result - one of the advantages of the inductive exploratory approach (not being constrained by the use of theory for model specification) that was harnessed in this study. Further research could look further into the effect image dissatisfaction has on other pro-environmental and pro-social behaviours.

\section{Methodological Discussion}

Using a mass transaction dataset to study human behaviour allowed for the examination of the predictors of a specific ecological behaviour in the real world. The inductive approach utilised in this study can be both hypothesis generating as well as testing. Considering a large number of potential explanatory features, while directly guarding against overfitting and procedural p-hacking, expanded the opportunity for knowledge discovery and reduced the likelihood of an unmeasured confounding variable affecting the results and their interpretation (Julious \& Mullee, 1994) (see The Simpson's Paradox (Simpson, 1951)). Overfitting and procedural p-hacking was mitigated through the use of cross-validation in conjunction with regularisation and recursive feature elimination. This methodology directly measures the reported relationships' ability to generalise, helping to ensure that the effects are more than just an artefact of the sample (Yarkoni \& Westfall, 2017). Statistical significance of variables were then considered, whilst directly controlling for the large number of variables though the use of the Benjamin-Hochberg false discovery procedure. As human interactions with the world are so complex, an almost infinite number of variables can influence behaviour. Thus, in using real world data, smaller effect sizes were found, as expected (Matz, Gladstone, \& Stillwell, 2017), compared to those that come from a controlled lab-based experiment.

There is great potential for big data to reveal previously undetectable insights about sub-groups underrepresented in society, or behavioural change over time. 
However, there is also the danger, if treated the same as small data, of over-fitting models and extracting false or inaccurate insights. There is a difference in extracting variable importance for prediction rather than for explanation (Grömping, 2009). For example, impulsivity may have not been a significant predictor of bag buying (as hypothesised) because of its negative correlation with age, and age's strong positive effect on bag buying. In the regression it is likely that age is masking the effect of it's correlates (impulsivity, self-control, shopping impulsivity, agreeableness, and neuroticism) (see Figure 3). Depending on the end goal, such variables could be reduced to a latent factor or principle component to improve prediction power (at the loss of fine grain information) (Harrell Jr, Lee, Califf, Pryor, \& Rosati, 1984); or modelled using Directed Acyclic Graph (DAG) Bayesian networks (Nielsen \& Jensen, 2009) or Structural Equation Modelling (SEM) to try to unpick the exact causal pathways.

How decisions get made in the real world necessitates that policy makers work with a simple and useful model, as they need to trust and understand the information on which they are basing key decisions. In such cases, finding a few key predictors is often more worthwhile than modelling a complex network of interrelated features. Thus the zero-order correlations in Figure 3 could be useful for practical applications when cost:benefit ratios need to be considered. For example, despite age and frugality being related, by incorporating domain knowledge and judgement it is concluded that age is more useful for targeting individuals than frugality (but it cannot be changed through interventions, like thriftiness potentially can). Age has a greater correlation coefficient with the dependent variable; trait levels are harder to detect within people, yet age is instantly observable; and if one causes the other, it is age than causes increased frugality, not the other way around (Roberts, Walton, \& Viechtbauer, 2006; Specht, Egloff, \& Schmukle, 2011). Yet, age cannot be manipulated through interventions in the same way thriftiness potentially can. Thus, the interaction between the variables also becomes important if interventions are to be targeted towards particular sub-groups of people in the real world.

Overall, this paper argues that big data is an important addition to the study of 
human behaviour in Psychology. However, researchers must utilise the appropriate methods of model specification and evaluation (such as K-fold cross validation and out of sample testing), to ensure models do not over-fit. This may require the use of non-traditional psychological methods or statistics (Breiman et al., 2001), but will help to minimise false positives and ensure the findings that emerge are replicable and generalise to a wider population.

\section{Summary}

Bans and levies are not the only mechanisms to reduce single use plastics (Xanthos \& Walker, 2017) - knowing whom and how best to target people is important to avoid a plateau, or future increases, in bag sales, as observed in Ireland (Clarke, 2014). This study has highlighted predictive features of regular bag buyers: namely being younger, spending more, being male, less frugal, high in openness, and being displeased with their appearance. Notably environmental concerns were not significant predictors. This profile is dissimilar from that of pro-environmental individuals in the literature and suggests that bag buying behaviour results less from concerns over global warming, and more from the ability to translate an intention to a behaviour. This is likely due to the forwards planning required for bringing personal bags to the store (Sun et al., 2017). It is also suspected that the bag buyers are more materialistic and consumerist as they spent more money in store and rate themselves lower in frugality. Whether these effects are caused by age or just correlates is not explicitly tested here, but is less important when identifying subgroups such as 'young people' for future campaigns to target. 


\section{References}

Abrahamse, W., Steg, L., Gifford, R., \& Vlek, C. (2009). Factors influencing car use for commuting and the intention to reduce it: A question of self-interest or morality? Transportation Research Part F: Traffic Psychology and Behaviour, 12(4), $317-324$.

Allison, P. (2012). When can you safely ignore multicollinearity? (https://statisticalhorizons.com/multicollinearity)

Anastasio, M., \& Nix, J. (2016). Plastic bag levy in ireland. (https://www.nidirect.gov.uk/articles/carrier-bag-levy)

Ando, K., Ohnuma, S., Blöbaum, A., Matthies, E., \& Sugiura, J. (2010). Determinants of individual and collective pro-environmental behaviors: Comparing germany and japan. Journal of environmental information science, 38(5), 21-32.

Arbuthnot, J. (1977). The roles of attitudinal and personality variables in the prediction of environmental behavior and knowledge. Environment and behavior, $9(2), 217-232$.

Arcury, T. A., \& Christianson, E. H. (1993). Rural-urban differences in environmental knowledge and actions. The Journal of Environmental Education, 25(1), 19-25.

Australia, C. U. (2015). Report on actions to reduce circulation of single-use plastic bags around the world: August 2015 (retrieved from australia).

Axon, S. (2017). "keeping the ball rolling": Addressing the enablers of, and barriers to, sustainable lifestyles. Journal of Environmental Psychology, 52, 11-25.

Balderjahn, I. (1988). Personality variables and environmental attitudes as predictors of ecologically responsible consumption patterns. Journal of business Research, $17(1), 51-56$.

Bamberg, S., \& Möser, G. (2007). Twenty years after hines, hungerford, and tomera: A new meta-analysis of psycho-social determinants of pro-environmental behaviour. Journal of environmental psychology, 27(1), 14-25.

Baumeister, R. F., Bratslavsky, E., Muraven, M., \& Tice, D. M. (1998). Ego depletion: Is the active self a limited resource? Journal of personality and social psychology, 
$74(5), 1252$.

Benjamini, Y., \& Hochberg, Y. (1995). Controlling the false discovery rate: a practical and powerful approach to multiple testing. Journal of the Royal statistical society: series B (Methodological), 57(1), 289-300.

Bishop, C. M. (2006). Pattern recognition and machine learning (information science and statistics) springer-verlag new york. Inc. Secaucus, NJ, USA.

Block, B. (2013). China reports 66-percent drop in plastic bag use. Eye on Earth, Worldwatch Institute. Retrieved November, 29.

Borden, R. J., \& Francis, J. L. (1978). Who cares about ecology? personality and sex differences in environmental concern 1. Journal of Personality, 46(1), 190-203.

Breiman, L., et al. (2001). Statistical modeling: The two cultures (with comments and a rejoinder by the author). Statistical science, 16(3), 199-231.

Carver, C. S., \& White, T. L. (1994). Behavioral inhibition, behavioral activation, and affective responses to impending reward and punishment: the bis/bas scales. Journal of personality and social psychology, 67(2), 319.

Chao, Y.-L., \& Lam, S.-P. (2011). Measuring responsible environmental behavior: Self-reported and other-reported measures and their differences in testing a behavioral model. Environment and Behavior, 43(1), 53-71.

Clapp, J., \& Swanston, L. (2009). Doing away with plastic shopping bags: international patterns of norm emergence and policy implementation. Environmental politics, $18(3), 315-332$.

Clarke, J. (2014). Plastic bags - the irish experience. Paper presented at the dialogue event "disposable bag", brussels (24/02/2014).

Convery, F., McDonnell, S., \& Ferreira, S. (2007). The most popular tax in europe? lessons from the irish plastic bags levy. Environmental and resource economics, $38(1), 1-11$.

Corral-Verdugo, V., Fraijo-Sing, B., \& Pinheiro, J. Q. (2006). Sustainable behavior and time perspective: Present, past, and future orientations and their relationship with water conservation behavior. Interamerican Journal of Psychology, 40(2), 
$139-147$.

Costa, P. T., \& MacCrae, R. R. (1992). Revised neo personality inventory (neo pi-r) and neo five-factor inventory (neo-ffi): Professional manual. Psychological Assessment Resources, Incorporated.

DAERA. (2018). Northern ireland carrier bag levy statistics.

(https://www.daera-ni.gov.uk/articles/

northern-ireland-carrier-bag-levy-statistics)

Dahl, F. A., Grotle, M., Benth, J. Š., \& Natvig, B. (2008). Data splitting as a countermeasure against hypothesis fishing: with a case study of predictors for low back pain. European journal of epidemiology, 23(4), 237-242.

Davidson, D. J., \& Freudenburg, W. R. (1996). Gender and environmental risk concerns: A review and analysis of available research. Environment and behavior, 28(3), 302-339.

DEFRA. (2018a). Plastic carrier bags: Gove sets out new measures to extend charge. (https://www.gov.uk/government/news/ plastic-carrier-bags-gove-sets-out-new-measures-to-extend-charge)

DEFRA. (2018b). Single-use plastic carrier bags charge: data in england for 2016 to 2017. (https://www.gov.uk/government/publications/ carrier-bag-charge-summary-of-data-in-england/single-use-plastic -carrier-bags-charge-data-in-england-for-2016-to-2017)

Diamantopoulos, A., Schlegelmilch, B. B., Sinkovics, R. R., \& Bohlen, G. M. (2003). Can socio-demographics still play a role in profiling green consumers? a review of the evidence and an empirical investigation. Journal of Business research, 56(6), $465-480$.

Diener, E., Lucas, R. E., Oishi, S., et al. (2002). Subjective well-being: The science of happiness and life satisfaction. Handbook of positive psychology, 2, 63-73.

Dunlap, R. E., Van Liere, K. D., Mertig, A. G., \& Jones, R. E. (2000). New trends in measuring environmental attitudes: measuring endorsement of the new ecological paradigm: a revised nep scale. Journal of social issues, 56 (3), 425-442. 
Edwards, C., \& Fry, J. M. (2011). Life cycle assessment of supermarket carrier bags. Environment Agency, Horizon House, Deanery Road, Bristol, BS1 5AH.

Fielding, K. S., \& Head, B. W. (2012). Determinants of young australians' environmental actions: The role of responsibility attributions, locus of control, knowledge and attitudes. Environmental Education Research, 18(2), 171-186.

Fraj, E., \& Martinez, E. (2006). Environmental values and lifestyles as determining factors of ecological consumer behaviour: an empirical analysis. Journal of Consumer Marketing, 23(3), 133-144.

Frick, J., Kaiser, F. G., \& Wilson, M. (2004). Environmental knowledge and conservation behavior: Exploring prevalence and structure in a representative sample. Personality and Individual differences, 37(8), 1597-1613.

Fuj, E. T., Hennessy, M., \& Mak, J. (1985). An evaluation of the validity and reliability of survey response data on household electricity conservation. Evaluation Review, 9(1), 93-104.

Gatersleben, B., Murtagh, N., \& Abrahamse, W. (2014). Values, identity and pro-environmental behaviour. Contemporary Social Science, 9(4), 374-392.

Gifford, R., \& Nilsson, A. (2014). Personal and social factors that influence pro-environmental concern and behaviour: A review. International Journal of Psychology, 49(3), 141-157.

Goldsmith, R. E., \& Flynn, L. R. (2015). The etiology of frugal spending: A partial replication and extension. Comprehensive Psychology, 4, 09-20.

Gosling, S. D., Rentfrow, P. J., \& Swann Jr, W. B. (2003). A very brief measure of the big-five personality domains. Journal of Research in personality, 37(6), 504-528.

GOV. (2015). Plastic bag numbers rise for the fifth year. (https://www.gov.uk/ government/news/plastic-bag-numbers-rise-for-the-fifth-year)

Grömping, U. (2009). Variable importance assessment in regression: linear regression versus random forest. The American Statistician, 63(4), 308-319.

Haoran, H. (2010). The effects of an environmental policy on consumers: lessons from the chinese plastic bag regulation. Institutionen för nationalekonomi med statistik, 
Handelshögskolan vid ....

Harrell Jr, F. E., Lee, K. L., Califf, R. M., Pryor, D. B., \& Rosati, R. A. (1984).

Regression modelling strategies for improved prognostic prediction. Statistics in medicine, 3(2), 143-152.

Hartig, T., Kaiser, F. G., \& Bowler, P. A. (2001). Psychological restoration in nature as a positive motivation for ecological behavior. Environment and behavior, 33(4), $590-607$.

Hartley, B. L., Thompson, R. C., \& Pahl, S. (2015). Marine litter education boosts children's understanding and self-reported actions. Marine pollution bulletin, 90(1-2), 209-217.

He, H. (2010). The effects of an environmental policy on consumers: Lessons from the chinese plastic bag regulation. rapport nr.: Working Papers in Economics 453.

Hines, J. M., Hungerford, H. R., \& Tomera, A. N. (1987). Analysis and synthesis of research on responsible environmental behavior: A meta-analysis. The Journal of environmental education, 18(2), 1-8.

Hirsh, J. B. (2010). Personality and environmental concern. Journal of Environmental Psychology, 30(2), 245-248.

Hirsh, J. B., \& Dolderman, D. (2007). Personality predictors of consumerism and environmentalism: A preliminary study. Personality and individual differences, 43(6), 1583-1593.

Honnold, J. A. (1984). Age and environmental concern some specification of effects. The Journal of Environmental Education, 16(1), 4-9.

Howard, G. S., Delgado, E., Miller, D., \& Gubbins, S. (1993). Transforming values into actions: Ecological preservation through energy conservation. The Counseling Psychologist, 21(4), 582-596.

Jackson, T. (2012). The challenge of sustainable lifestyles. In State of the world 2008 (pp. 45-60). Routledge.

Jakovcevic, A., Steg, L., Mazzeo, N., Caballero, R., Franco, P., Putrino, N., \& Favara, J. (2014). Charges for plastic bags: Motivational and behavioral effects. Journal 
of Environmental Psychology, 40, 372-380.

Jambeck, J. R., Geyer, R., Wilcox, C., Siegler, T. R., Perryman, M., Andrady, A., ... Law, K. L. (2015). Plastic waste inputs from land into the ocean. Science, $347(6223), 768-771$.

(http://science.sciencemag.org/content/347/6223/768) doi:

$10.1126 /$ science. 1260352

Joireman, J. A., Van Lange, P. A., \& Van Vugt, M. (2004). Who cares about the environmental impact of cars? those with an eye toward the future. Environment and Behavior, 36(2), 187-206.

Julious, S. A., \& Mullee, M. A. (1994). Confounding and simpson's paradox. Bmj, $309(6967), 1480-1481$.

Kaiser, F. G., Wölfing, S., \& Fuhrer, U. (1999). Environmental attitude and ecological behaviour. Journal of environmental psychology, 19(1), 1-19.

Kalof, L., Dietz, T., Guagnano, G., \& Stern, P. C. (2002). Race, gender and environmentalism: The atypical values and beliefs of white men. Race, Gender $\mathcal{G}$ Class, 112-130.

Klineberg, S. L., McKeever, M., \& Rothenbach, B. (1998). Demographic predictors of environmental concern: It does make a difference how it's measured. Social science quarterly, 734-753.

Kormos, C., \& Gifford, R. (2014). The validity of self-report measures of proenvironmental behavior: A meta-analytic review. Journal of Environmental Psychology, 40, 359-371.

Lanzini, P., \& Thøgersen, J. (2014). Behavioural spillover in the environmental domain: an intervention study. Journal of Environmental Psychology, 40, 381-390.

Lastovicka, J. L., Bettencourt, L. A., Hughner, R. S., \& Kuntze, R. J. (1999). Lifestyle of the tight and frugal: Theory and measurement. Journal of consumer research, $26(1), 85-98$.

Markowitz, E. M., Goldberg, L. R., Ashton, M. C., \& Lee, K. (2012). Profiling the "pro-environmental individual": A personality perspective. Journal of personality, 
$80(1), 81-111$.

Matz, S. C., Gladstone, J. J., \& Stillwell, D. (2017). In a world of big data, small effects can still matter: a reply to boyce, daly, hounkpatin, and wood (2017). Psychological science, 28(4), 547-550.

McCrae, R. R. (1993). Openness to experience as a basic dimension of personality. Imagination, Cognition and Personality, 13(1), 39-55.

McFadden, D., et al. (1973). Conditional logit analysis of qualitative choice behavior.

Milfont, T. L., \& Sibley, C. G. (2012). The big five personality traits and environmental engagement: Associations at the individual and societal level. Journal of Environmental Psychology, 32(2), 187-195.

Monaghan, A. (2018). Which items can't be recycled?

(https : //www. theguardian. com/environment/2018/mar/16/

which-items-cant-be-recycled-plastic-bags-coffee-cups)

NEMA. (2018). Ban on plastic carrier bags.

(https://www.nema.go.ke/index.php?option=com_content\&view= article\&id=102: government-bans-plastic-carriers\&catid=10\&Itemid=246)

Ng, A. Y. (2004). Feature selection, 11 vs. 12 regularization, and rotational invariance. In Proceedings of the twenty-first international conference on machine learning (p. 78).

Nielsen, T. D., \& Jensen, F. V. (2009). Bayesian networks and decision graphs. Springer Science \& Business Media.

O'brien, R. M. (2007). A caution regarding rules of thumb for variance inflation factors. Quality \& quantity, 41(5), 673-690.

Pedregosa, F., Varoquaux, G., Gramfort, A., Michel, V., Thirion, B., Grisel, O., ... Duchesnay, E. (2011). Scikit-learn: Machine learning in Python. Journal of Machine Learning Research, 12, 2825-2830.

Pepper, M., Jackson, T., \& Uzzell, D. (2011). An examination of christianity and socially conscious and frugal consumer behaviors. Environment and Behavior, 43(2), 274-290. 
Pettus, A. M., \& Giles, M. B. (1987). Personality characteristics and environmental attitudes. Population and Environment, 9(3), 127-137.

Poortinga, W., Sautkina, E., Thomas, G. O., \& Wolstenholme, E. (2016). The english plastic bag charge: Changes in attitudes and behaviour.

Poortinga, W., Whitmarsh, L., \& Suffolk, C. (2013). The introduction of a single-use carrier bag charge in wales: Attitude change and behavioural spillover effects. Journal of Environmental Psychology, 36, 240-247.

Reimers, S., Maylor, E. A., Stewart, N., \& Chater, N. (2009). Associations between a one-shot delay discounting measure and age, income, education and real-world impulsive behavior. Personality and Individual Differences, 47(8), 973-978.

Roberts, B. W., Walton, K. E., \& Viechtbauer, W. (2006). Patterns of mean-level change in personality traits across the life course: a meta-analysis of longitudinal studies. Psychological bulletin, 132(1), 1.

Rook, D. W., \& Fisher, R. J. (1995). Normative influences on impulsive buying behavior. Journal of consumer research, 22(3), 305-313.

Royer, S.-J., Ferron, S., Wilson, S. T., \& Karl, D. M. (2018). Production of methane and ethylene from plastic in the environment. PloS one, 13(8), e0200574.

Scottish Government. (2015). Scotland's single use carrier bag usage drops by 650 million since charge was introduced.

(https://www.webarchive.org.uk/wayback/archive/20181023201037/ https://news.gov.scot/news/bags-of-success)

Sharp, A., Høj, S., \& Wheeler, M. (2010). Proscription and its impact on anti-consumption behaviour and attitudes: the case of plastic bags. Journal of Consumer Behaviour, 9(6), 470-484.

Simpson, E. H. (1951). The interpretation of interaction in contingency tables. Journal of the Royal Statistical Society: Series B (Methodological), 13(2), 238-241.

Smithers, R. (2016). England's plastic bag usage drops $85 \%$ since $5 p$ charge introduced. (https://www. theguardian.com/environment/2016/jul/30/england-plastic -bag-usage-drops-85-per-cent-since-5p-charged-introduced) 
Specht, J., Egloff, B., \& Schmukle, S. C. (2011). Stability and change of personality across the life course: The impact of age and major life events on mean-level and rank-order stability of the big five. Journal of personality and social psychology, $101(4), 862$.

Spence, A., Poortinga, W., \& Pidgeon, N. (2012). The psychological distance of climate change. Risk Analysis: An International Journal, 32(6), 957-972.

Sun, Y., Wang, S., Li, J., Zhao, D., \& Fan, J. (2017). Understanding consumers' intention to use plastic bags: using an extended theory of planned behaviour model. Natural Hazards, 89(3), 1327-1342.

Swami, V., Chamorro-Premuzic, T., Snelgar, R., \& Furnham, A. (2011). Personality, individual differences, and demographic antecedents of self-reported household waste management behaviours. Journal of Environmental Psychology, 31(1), $21-26$.

Tangney, J. P., Boone, A. L., \& Baumeister, R. F. (2018). High self-control predicts good adjustment, less pathology, better grades, and interpersonal success. In Self-regulation and self-control (pp. 181-220). Routledge.

Tapia-Fonllem, C., Corral-Verdugo, V., Fraijo-Sing, B., \& Durón-Ramos, M. (2013). Assessing sustainable behavior and its correlates: A measure of pro-ecological, frugal, altruistic and equitable actions. Sustainability, 5(2), 711-723.

Thøgersen, J., \& Ölander, F. (2003). Spillover of environment-friendly consumer behaviour. Journal of environmental psychology, 23(3), 225-236.

Thomas, G. O., Poortinga, W., \& Sautkina, E. (2016). The welsh single-use carrier bag charge and behavioural spillover. Journal of Environmental Psychology, 47, $126-135$.

Thomas, G. O., Sautkina, E., Poortinga, W., Wolstenholme, E., \& Whitmarsh, L. (2019). The english plastic bag charge changed behavior and increased support for other charges to reduce plastic waste. Frontiers in Psychology, 10.

Todd, S., \& Lawson, R. (2003). Towards an understanding of frugal consumers. Australasian Marketing Journal (AMJ), 11(3), 8-18. 
Urien, B., \& Kilbourne, W. (2011). Generativity and self-enhancement values in eco-friendly behavioral intentions and environmentally responsible consumption behavior. Psychology \&6 marketing, 28(1), 69-90.

Van de Mortel, T. F., et al. (2008). Faking it: social desirability response bias in self-report research. Australian Journal of Advanced Nursing, The, 25(4), 40.

Van der Linden, S., Maibach, E., \& Leiserowitz, A. (2015). Improving public engagement with climate change: Five "best practice" insights from psychological science. Perspectives on Psychological Science, 10(6), 758-763.

Welsh Government. (2016). Northern ireland carrier bag levy statistics. (https://gov.wales/topics/environmentcountryside/epq/ waste_recycling/substance/carrierbags/?lang=en)

Wiseman, M., \& Bogner, F. X. (2003). A higher-order model of ecological values and its relationship to personality. Personality and Individual differences, 34(5), $783-794$.

WRAP. (2015). Wrap announces new carrier bag figures. (http://www.wrap.org.uk/2015_carrier_bag_figures)

Xanthos, D., \& Walker, T. R. (2017). International policies to reduce plastic marine pollution from single-use plastics (plastic bags and microbeads): a review. Marine pollution bulletin, 118(1-2), 17-26.

Yarkoni, T., \& Westfall, J. (2017). Choosing prediction over explanation in psychology: Lessons from machine learning. Perspectives on Psychological Science, 12(6), $1100-1122$.

Zelezny, L. C., Chua, P.-P., \& Aldrich, C. (2000). New ways of thinking about environmentalism: Elaborating on gender differences in environmentalism. Journal of Social issues, 56(3), 443-457. 
PSYCHOLOGICAL AND DEMOGRAPHIC PREDICTORS OF PLASTIC BAG CONSUMPTION

Appendix A

Link to the full survey

A copy of the full survey that was sent to participants can be found here: «removed for anonymity during review». 
Appendix B

Meta-Parameters

The meta (or hyper) parameter values considered in the grid search for the logistic regression were: the type of regression (characterised by different loss functions and regularisation schemes); the cost (or 'C'); and the tolerance (epsilon). The grid search iterated through the following values for each meta parameter. For the type of regression: L2-regularised logistic regression (primal), L2-regularized L2-loss support vector classification (dual), L2-regularized L2-loss support vector classification (primal), L2-regularized L1-loss support vector classification (dual), L1-regularized logistic regression, and L2-regularized logistic regression (dual). Different cost values were: $1,2,3,4$. The different tolerance values were 0.0001,0.001,0.01,0.1,0.5. This grid was finalised after ensuring that a value at either end of the grid, for any of the parameters, had not been selected (so the algorithm was not being limited by the parameter values being manually provided). 
PSYCHOLOGICAL AND DEMOGRAPHIC PREDICTORS OF PLASTIC BAG CONSUMPTION

Appendix C

Full results table 
Table C1

Full results table from the logistic regression model predicting frequent bag buying. Table ordered by p-value from low to high.

\begin{tabular}{|c|c|c|c|}
\hline & Independent Variables & Beta coefficient & $p$-value \\
\hline 1 & Age & -0.600 & 0 \\
\hline 2 & Average Monthly Spend (£) & 0.430 & 0 \\
\hline 3 & Gender: Male & 0.210 & 0 \\
\hline 4 & Frugality & -0.210 & 0 \\
\hline 5 & Openness & 0.140 & 0.001 \\
\hline 6 & Region: West Midlands & 0.120 & 0.001 \\
\hline 7 & SM7 & -0.130 & 0.001 \\
\hline 8 & Region: North West & 0.120 & 0.002 \\
\hline 9 & Region: North East & 0.110 & 0.002 \\
\hline 10 & Region: East Anglia & 0.100 & 0.004 \\
\hline 11 & Shopping frequency: Every day & -0.090 & 0.007 \\
\hline 12 & Agreeableness & 0.090 & 0.011 \\
\hline 13 & Region: London & 0.080 & 0.019 \\
\hline 14 & SM6 & 0.090 & 0.020 \\
\hline 15 & Shopping frequency: Once in 2-3 months & -0.080 & 0.021 \\
\hline 16 & Income: Prefer not to say & -0.100 & 0.025 \\
\hline 17 & Shopping frequency: Once a month & -0.080 & 0.027 \\
\hline 18 & BAS-RR & 0.100 & 0.030 \\
\hline 19 & Live with: Solo, children & 0.080 & 0.032 \\
\hline 20 & Marital status: Divorced & 0.080 & 0.036 \\
\hline 21 & Qualification: GCSE & 0.090 & 0.037 \\
\hline 22 & Income: $£ 150,000$ or more & -0.070 & 0.038 \\
\hline 23 & SM9 & 0.070 & 0.046 \\
\hline 24 & Region: Yorkshire & 0.070 & 0.047 \\
\hline 25 & Time preference: $£ 40$ now, not $£ 70$ in 3 months & 0.100 & 0.049 \\
\hline 26 & Region: South East & 0.070 & 0.054 \\
\hline 27 & Marital status: Widowed & 0.060 & 0.066 \\
\hline 28 & Qualification: School & 0.070 & 0.074 \\
\hline 29 & Marital status: Other & 0.060 & 0.091 \\
\hline 30 & Shopping frequency: Twice a week & 0.060 & 0.091 \\
\hline 31 & $\mathrm{SM} 2$ & 0.070 & 0.094 \\
\hline 32 & SM11 & -0.070 & 0.096 \\
\hline 33 & Occupation: Skilled manual worker & 0.060 & 0.110 \\
\hline 34 & Region: Wales & 0.060 & 0.118 \\
\hline 35 & Live with: Partner, children & 0.060 & 0.121 \\
\hline 36 & Region: East Midlands & 0.060 & 0.125 \\
\hline 37 & SM3 & 0.060 & 0.127 \\
\hline 38 & Qualification: Postgraduate & 0.060 & 0.143 \\
\hline 39 & Region: Northern Ireland‘ & 0.050 & 0.153 \\
\hline 40 & Shopping frequency: More than twice a week & 0.050 & 0.167 \\
\hline 41 & Card usage: Never & 0.070 & 0.169 \\
\hline 42 & Occupation: self-employed/own business & 0.050 & 0.175 \\
\hline 43 & Marital status: Single & -0.060 & 0.183 \\
\hline 44 & SM4 & 0.050 & 0.192 \\
\hline 45 & Qualification: PhD & -0.040 & 0.205 \\
\hline 46 & SM5 & 0.050 & 0.208 \\
\hline
\end{tabular}




\begin{tabular}{|c|c|c|c|}
\hline & Independent Variables & Beta coefficient & $p$-value \\
\hline 47 & Time preference: $£ 55$ now, not $£ 70$ in 3 months & 0.050 & 0.243 \\
\hline 48 & Card usage: Hardly ever & 0.040 & 0.267 \\
\hline 49 & Well-being & -0.040 & 0.270 \\
\hline 50 & Extroversion & 0.040 & 0.307 \\
\hline 51 & Qualification: AS-level & -0.030 & 0.314 \\
\hline 52 & Qualification: A-level & 0.040 & 0.316 \\
\hline 53 & Shopping Impulsivity & 0.050 & 0.317 \\
\hline 54 & Region: Scotland & 0.040 & 0.318 \\
\hline 55 & Region: South West & 0.030 & 0.319 \\
\hline 56 & Income: $£ 35,000$ to $£ 49,999$ & -0.040 & 0.351 \\
\hline 57 & Occupation: Retired/Semi-retired & -0.040 & 0.357 \\
\hline 58 & Occupation: Full-time carer of other household member & 0.030 & 0.392 \\
\hline 59 & SM1 & -0.040 & 0.413 \\
\hline 60 & Shopping frequency: Every 6 months or less & -0.030 & 0.432 \\
\hline 61 & Qualification: Advanced & -0.030 & 0.440 \\
\hline 62 & Occupation: Homemaker & 0.030 & 0.474 \\
\hline 63 & Occupation: Casual worker & 0.020 & 0.508 \\
\hline 64 & Income: $£ 25,000$ to $£ 34,999$ & -0.030 & 0.527 \\
\hline 65 & Card usage: Most of the time & 0.020 & 0.568 \\
\hline 66 & Live with: Adults (non-family) & 0.020 & 0.571 \\
\hline 67 & Live with: Adults (family) & 0.020 & 0.620 \\
\hline 68 & Qualification: BTEC & 0.020 & 0.636 \\
\hline 69 & Shopping frequency: Once every 4-6 months & -0.020 & 0.644 \\
\hline 70 & Income: $£ 50,000$ to $£ 74,999$ & -0.020 & 0.647 \\
\hline 71 & Card usage: Sometimes & -0.020 & 0.651 \\
\hline 72 & Qualification: Masters & 0.020 & 0.659 \\
\hline 73 & Marital status: Separated & -0.010 & 0.672 \\
\hline 74 & Emotional Stability & -0.020 & 0.672 \\
\hline 75 & Time preference: $£ 25$ now, not $£ 70$ in 3 months & -0.020 & 0.686 \\
\hline 76 & Occupation: Unemployed/long-term sickness & -0.010 & 0.701 \\
\hline 77 & BAS-D & -0.020 & 0.709 \\
\hline 78 & Occupation: Other & 0.010 & 0.715 \\
\hline 79 & Occupation: Semi/unskilled manual work & 0.010 & 0.716 \\
\hline 80 & Income: $£ 100,000$ to $£ 149,999$ & -0.010 & 0.721 \\
\hline 81 & Conscientiousnss & 0.010 & 0.726 \\
\hline 82 & SM10 & 0.010 & 0.731 \\
\hline 83 & Occupation: Higher managerial/professional/admin. & 0.010 & 0.769 \\
\hline 84 & Occupation: Student & -0.010 & 0.782 \\
\hline 85 & Self-control & -0.010 & 0.795 \\
\hline 86 & Occupation: Supervisory/clerical/junior manager./admin & 0.010 & 0.824 \\
\hline 87 & SM8 & 0.010 & 0.835 \\
\hline 88 & Qualification: Other & 0.010 & 0.851 \\
\hline 89 & Income: $£ 75,000$ to $£ 99,999$ & 0.010 & 0.888 \\
\hline 90 & Shopping frequency: Once a week & 0 & 0.902 \\
\hline 91 & Shopping frequency: Don't know & 0.090 & 0.904 \\
\hline 92 & BAS-FS & 0 & 0.933 \\
\hline
\end{tabular}


Note: Significance levels and beta coefficents are rounded to three decimal places. Shopping motivation (SM) questions: SM1= 'I would rather stick to a brand I usually buy than try something I am not very sure of.' SM2= 'I enjoy taking chances in buying unfamiliar brands just to get some variety in my purchases.' $S M 3=$ 'If I like a brand I rarely switch from it just to try something new.' $S M_{4}=$ 'I would not mind paying more in order to get a high quality product.' $S M 5=$ 'I only buy products I trust.' $S M 6=$ 'Product Quality is extremely important to me.' $S M 7=$ 'I am pleased about the way I look.' SM8= 'When I feel good about my looks, I am happier and have a better outlook on life.' SM9= "Whenever I see a mirror, I "check myself out" to see how I look.' SM10= 'Environmental considerations affect the products that I purchase.' SM11= 'I am concerned about climate change (also known as global warming).' 